\title{
Gastronomi Kültürünün İnşası ve Dönüşümünde Televizyon: Masterchef Türkiye ve The Taste Türkiye Programları Örneği
}

\author{
Cem $\operatorname{Tutar}^{1}\left(\mathbb{D}\right.$, Durmuş Durukan² $^{(1)}$
}

\section{Öz}

1970'li yıllarla birlikte kapitalizm, üretim temelli bir yapıdan tüketim temelli bir yapıya doğru dönüşüm yaşarken toplumsal ve kültürel alanda yaşanan gelişmeler sonucunda yeniden üretim, gösteri ve eğlence teması toplumsal alanda dolaşıma girmiştir. Gösteri, kültürel alanda temel varoluş etkinliğinin bir parçası olarak özellikle kitle iletişim araçları üzerinden yaratılan semantik alanda ideolojik bir işleve sahiptir. Neoliberal piyasa ekonomisinin desteklediği tüketim toplumunda gündelik hayat kapitalist saiklere göre planlanırken sistemin devamı için gerekli olan bir insan tipi televizyon üzerinden verilen uzmanlık bilgileri dâhilinde üretilmektedir. Tüketim toplumunda yemek kültürü de şekil değiştirerek insanın yaşamını sürdürmesi için gerekli olan fizyolojik gereksinimi giderme biçiminden uzaklaşarak postmodern dünyanın gereklerine göre yapılandırılmış gastronomi kültürü ile postmodern dünyanın gündelik hayatının sürdürülmesinde işlevsel bir araca dönüşmüştür. Televizyon bu kültürü üreten ve yaygınlaştıran önemli bir araçtr. Bu toplumsal ve kültürel yapı içerisinde gastronomi alanı kimi zaman gösteri ve eğlence teması içerisinde şov dünyasının bir parçası olma ya da neoliberal pazar ekonomisi içerisinde yeni ve kazançlı bir gelir kapısı olarak televizyonda verilen temsiller üzerinden sunulmaktadır. Özellikle uluslararası alanda dolaşıma giren bir program formatı olarak reality yarışma programları bu anlamda ideolojik bir işleve haizdir. Bu programlar bir yandan küresel düzeyde işleyen tüketim ekonomisi içerisinde bireyin gündelik yaşamının örgütlenmesini ve yeni bir insan tipinin kurgulanmasını sağlarken diğer yandan eklektik, postmodern bir yeme içme kültürünü dolaşıma sokmaktadır. Bu çalışmada ulusal televizyon kanalları içerisinde reality programların alt türleri dikkate alınarak amaca yönelik bir örneklem oluşturulmakta ve bu yolla tespit edilen programların tüketim toplumu ve gösterinin ideolojik işleviyle ilişkisi, alana ait kuramsal bir çerçeve üzerinden irdelenmektedir.

Anahtar Kelimeler: Tüketim Toplumu • Neoliberalizm • Yemek Kültürü • Gastronomi • Yarışma Programları • Reality Programları

Television in the Construction and Transformation of Gastronomic Culture: The Cases of MasterChef Turkey and The Taste Türkiye Programs

\section{Abstract}

Together with capitalism's transformation from a production-based structure to a consumption-based structure, as a result of the social and cultural developments in the 1970s, the themes of reproduction, performance and entertainment also entered into circulation in the social field. As part of the basic existential activity in the cultural field, performance has an ideological function, especially in the semantic area created by mass media. While daily life has been planned according to capitalist motives in consumer society with the support of the neoliberal market economy, the type of human that is required for the system's continuation is produced within the knowledge of expertise television provides. Food culture has also changed its shape and diverged from the ways it used to meet the physiological needs required for humans' survival in consumer society; the gastronomic culture structured according to the requirements of the postmodern world has turned food culture into a functional tool for mainting the daily life of the postmodern world. The field of gastronomy is sometimes presented in this social and cultural structure through television shows as part of show business under the themes of performance and entertainment, or as a new and lucrative income channel in the neoliberal market economy. Reality game shows, as a program format that has entered into circulation in the international arena in particular, have an ideological function in this sense. While these programs, on the one hand, allow daily lives to be organized and a new type of person to be constructed within the consumption economy, functioning at the global level, these programs on the other hand circulate an eclectic, postmodern gastronomic culture. This study, has formed a purposeful sample by taking into consideration the sub-types of reality programs within national television channels, and examines the relations the programs identified in this way have with consumer society as well as the ideological function of these programs' performances using a field-theory framework.

Keywords: Consumption society $\bullet$ Neoliberalism $\bullet$ Food culture $\bullet$ Gastronomy $\bullet$ Game shows $\bullet$ Reality programs

1 Sorumlu Yazar: Cem Tutar (Dr. Öğr. Üyesi), Üsküdar Üniversitesi, İletişim Fakültesi, Görsel İletişim Tasarımı Bölümü, İstanbul, Türkiye. Eposta: cem.tutar@uskudar.edu.tr ORCID: 0000-0002-4547-6171

2 Durmuş Durukan, Üsküdar Üniversitesi Sosyal Bilimler Enstitüsü Medya ve Kültürel Çalışmaları Anabilim Dalı, İstanbul, Türkiye. Eposta: dr.ddurukan@gmail.com ORCID: 0000- 0001- 8353- 1728

Attf: Tutar, C. ve Durukan, D. (2020). Gastronomi kültürünün inşası ve dönüşümünde televizyon: Masterchef Türkiye ve The Taste Türkiye programları örneği. İstanbul Üniversitesi Sosyoloji Dergisi, 40, 339-364. https://doi.org/10.26650/SJ.2020.40.1.0032 


\section{Extended Summary}

When analyzing the historical course of capitalism its domination seen to have been mainted over various historical periods, from the mercantilist to liberal forms throughout the 19th century, to the state-centered forms of the 20th century and the neoliberal global forms of the present (Postone, 2018, p. 11). This new social form, in which capitalism has maintained its development due to its structure, and where the economy and politics match each other structurally, is called neoliberalism. In short, living in a neoliberal economic and social structure means that everything is made financial. In this case, the idea that the economy has deepened its control over the state apparatus and daily life just as in all other fields is dominant. This has also brought an everincreasing fluctuation to global-exchange relationships. This situation is interpreted as a shift of power from the production to the finance world (Harvey, 2015, p. 41). Studies in the field of sociology, emphasize this new form of capitalism to have transformed the economic structure in the 1970s into a consumption-oriented order in place of a production-based social structure. As a result of this transformation in the economic and social fields, the themes of reproduction, performance, and entertainment gained functionality in the cultural field. While mass media serves to spread the dominant ideology in the social field through its vehicles of communication, it also has instrumental importance in legitimizion the ideology between the rulers and the masses based on consent.

While daily life is planned according to capitalist motives in consumer societies with the support of neoliberal market economies, the knowledge of expertise that television provides produces the type of human required for the system. Lefebvre (2010, p. 122), stating that the ideology of the meta has become a collective activity in the consumer society, mentioned television's function in daily life as a technical instrument as part of the meta of programming for consumption. Television has gradually reached the status of "meta-medium" as a superior instrument in modern and postmodern societies and has become an instrument that directs not only human knowledge of the world but also human knowledge about the ways of knowing (Postman, 2004, p. 92). In this entire process, the cultural field can be defined as a show area that places shows into circulation as a kind of social relationship. Debord (2006, pp. 43, 161) emphasized that ideology has also turned into a metaphysical concept that exists in reality only in the mind, as a separate type of meta and that specialization and mass media are what shows are based on.

As in many field, the changes and transformations experienced in the social field have changed and transformed gastronomic culture (production, marketing, consumption). With these changes, nutrition culture, like other fields, has becomes articulated to neoliberal economic planes with consumption having a central location. Due to historical and social changes, nutrition and food are seen to have been transformed from a 
physiological need to a large industrial structure in the current age. Accordingly, nutrition and food are emphazied to have become an indispensable part of human relations (Akarçay, 2016, p. 17). In this context, the food and beverage culture in consumer society can be said to have transformed into a functional instrument for maintaining daily life with gastronomic culture being structured according to the requirements of the postmodern world. The field of gastronomy is sometimes presented through television shows as a part of show business under the themes of performance and entertainment, or as a new and lucrative income channel in the neoliberal market economy.

Kaplan (1992, p. 52) emphasized television to be an instrument of cultural expression just like a storyteller in contemporary societies. As a medium where the dominant values of the age are circulated into the social arena with fictional or non-fictional content television broadcasting has currently entered a structual transformation experiencing a change from fictional production to factual reality productions that deal with ordinary people in everyday life.

Reality programs and their subtypes emerged during the beginning of the 21st century within the television industry as product of the socio-economic and cultural structure of the times. The result of a confusing and multi-branched period of time, reality programming owes its widespread success to the predominant economic developments and the emergence of deregulations in the field of broadcasting. A special nod must also be made to the neoliberal economic planning within developed capitalist society and to media's spread of consumerism as a lifestyle as the major factors contributing to the success of such programming. In the eclectic sense, reality programing has played a mediating role form a globalized cosmopolitan culture (Lewis, 2010, pp. 190-195; Deery, 2012, pp. 2-3; Ganguly, 2012, pp. 323, 342). This study, has formed a purposeful sample by taking into consideration the sub-types of reality programs within national television channels. Using the field-theory framework, the study qualitatively analyzes the relations programs identified in this have way with consumer society as well as the ideological function of performance.

In the neoliberal economic stage that todays's capitalism has reached consumer activity and the individual's universal life surrounded by images constitute the basic feature of the cultural field. Reality programs, which themselves have a hybrid program format in television broadcasting, also have an ideological meaning as a hybrid cultural form. Gastronomic game shows, in which a cosmopolitan world culture is put into circulation through the field of nutrition, have the general characteristics of this type of program, yet also have a deeper meaning in the social and cultural senses. First of all, reality game shows, just like all television forms, are seen to tell the audience a story and a mythos. In this program format, where ordinary people in daily life are the subjects, individual achievements and life stories are brought to the screen with the 
element of interest in the foreground. Just as in fictional productions, reality programs with factual content additionally have a dramatic narrative. Reality game shows contain moments of relaxation or catharsis that result from fulfilling a task and also contain the elements of curiosity, delay, tension and dramatic effect that are in parallel with realizing these tasks.

Reality game shows have these features as technical or formal codes, but they also function as a cultural phenomenon. In the neoliberal market economy, the young population has great interest in the field of gastronomy, which is presented nowadays as a lucrative income area. The culinary profession, which had previously belonged to lower income groups socio-economically, and had offered a professional experience, has now become an area of interest and professional skill accepted by all walks of society through the mediation of the consent-based guiding elements throughout the country. In social acceptance, knowledge of gastronomic expertise is instilled into the individual rather than into the culinary profession. Instead of being a master of professional experience based on a life-long project, chefs are designed in television programs or in daily life workshops by purchasing short-term experiences. The reason for this situation is the idea that in cases where economic and social uncertainties have come to the fore in the neoliberal period, individuals will transform their knowledge of gastronomic expertise into a valid and profitable profession as a life project. The mass media, in general and television in particular share in the social field through media the knowledge of expertise the examples and representations of chefs who have become successful in the field of gastronomy at a young age. Thus, while the field of gastronomy is shown as a lucrative area within consumer society, individual life stories are meanwhile presented to the audience using an interesting fiction within the show format of the program.

Recent studies in the field of mass communication have emphasized social meaning to be constructed in the process of the bilateral interactions between individual and mass media. In this context, reproducing the capitalist system becomes possible and the ideology of consumption is legitimized, especially in the process of the communicative dialogues established among television, the field of gastronomy and individuals as a technical instrument. In addition, gastronomic game shows point to an area where social meaning has dissolved and disappeared into entertainment content as part of a discourse of holistic performance. 


\section{Gastronomi Kültürünün İnşası ve Dönüşümünde Televizyon: Masterchef Türkiye ve The Taste Türkiye Programları Örneği}

Kapitalizmin tarihsel seyrine bakıldığında sermayenin tahakkümünün, merkantilist biçimlerden 19. yüzyıl boyunca liberal, 20.yüzyılda devlet merkezli ve günümüzde ise neoliberal küresel biçimlere kadar çeşitli formlarda mevcudiyetini sürdürdüğü görülmektedir (Postone, 2018, s. 11). Kapitalizmin yapısı gereği gelişimini sürdürerek, ekonomi-politik yapısıyla günümüzde ulaştığı toplumsal yeni formuna neoliberalizm adı verilmiştir. Kısacası, neoliberalleşmek demek, her şeyin finansallaşması olarak vurgulanmıştır. Bu dönemde ekonominin diğer bütün alanlarda olduğu gibi devlet aygıtı ve gündelik yaşam üzerindeki kontrolünü de derinleştirdiği düşüncesi hâkimdir (Harvey, 2015, s. 41). 1970'li y1llarla birlikte kapitalizmin bu yeni formunun toplumsal alanı üretim temelli bir yapıdan tüketim odaklı bir düzene dönüştürdüğü vurgulanmaktadır. Toplumsal ve kültürel alanlarda yaşanan bu yeni gelişmeler dâhilinde yeniden üretim, gösteri ve eğlence temaları üzerinden toplumsal alanda rızanın sağlanmasında kitle iletişim araçları ideolojik bir işleve haizdir.

Neoliberal piyasa ekonomisinin desteklediği tüketim toplumunda, gündelik hayat kapitalist saiklere göre planlanırken, sistemin devamı için gerekli olan bir insan tipi televizyon üzerinden verilen uzmanlık bilgileri dâhilinde üretilmektedir. Lefebvre, metânın ideolojisinin tüketim toplumunda kolektif etkinlik haline geldiğini belirterek televizyonun teknik bir araç olarak gündelik hayatın tüketime programlanmasında işlevsel bir yeri olduğunu belirtmektedir (2010, s. 122). Bu bağlamda televizyon modern ve ötesi toplumlarda giderek bir üst araç "meta-medium" statüsüne ulaşarak yalnızca dünyaya ilişkin bilgilerimizi değil aynı zamanda bilme yollarına ilişkin bilgimizi de yönlendiren bir araç statüsüne yükselmiştir (Postman, 2004, s. 92). Tüm bu süreçte kültürel alanının bir gösteri alanı olarak tanımlanması ve gösterinin toplumsal bir ilişki çeşidi olarak dolaşıma sokulması söz konusudur. Debord, gösterinin temelinde uzmanlaşma ve kitle iletişim araçları olduğunu vurgulayarak ideolojinin de metalaştığını vurgulamaktadır (2006, s. 43- s. 161). Debord, ideolojinin metalaşması kavramıyla tüketim kültüründeki her türlü nesne ve bireyler arası ilişki kalıplarının para ekonomisine eklemlenmiş bir şekilde sistem tarafından üretildiğini vurgulamaktadır.

Murat Belge, ideolojinin insan hayatında her şeyin içerisine karışabilir olacağına dikkat çekmektedir. Ulusların yediği yemekler ve yemek yeme üslupları da dönemin egemen ideolojisiyle ilişki içerisindedir. Bir ulusal mutfak, sadece ulusal ekonominin ürünü olmayıp, bir dünya görüşünün tezahürüdür. Bu konuda Claude Lévi-Strauss'un; bir toplumun yemek pişirme yolu, bilincinde olmadan yapılarını tercüme ettiği bir dil gibidir, söylemine yer vermektedir (2016, s. 15). Gastro-tüketim etkinliklerini popüler kültür içerisinde temel alarak yemeğin kültürel göstergelerini analiz eden İlkay Kanık, toplumsal değişim süreciyle birlikte, beslenme biçimlerimizin kodlarının; yani kültürlerinin de değiştiğine dikkat çekmektedir. Buna göre kitlesel olarak 
öğretilen gastro ihtiyaçlar ve bu ihtiyaçları gidererek elde edilen hazlar kültürel ürünleri üretenler tarafından belirlenmektedir (2016, s. 10). Kanık'ın açıklaması iletişim çalışmalarında kitle kültürü kavramını ortaya koyan Frankfurt Okulu eleştirmenlerinin söylemleriyle uyumludur. Toplumsal alanda yaşanılan değişim ve dönüşümler birçok alanda olduğu gibi yemek kültürünü de değiştirip dönüştürmektedir. Sonuçta beslenme kültürü de neoliberal ekonomik düzleme eklemli hale gelerek tüketim toplumu içerisinde anlam kazanmaktadır. Tarihsel ve toplumsal değişmelere bağlı olarak çağımızda beslenme ve yemeğin fizyolojik bir gereksinim olmaktan çıkartılarak büyük bir endüstriyel yapıya dönüştüğü görülmektedir. Buna bağlı olarak ise bu alan insan ilişkilerinin vazgeçilmez bir parçası haline gelmiştir (Akarçay, 2016, s. 17). Bu bağlamda tüketim toplumunda yeme-içme kültürünün postmodern dünyanın gereklerine göre yapılandırılmış gastronomi kültürü içerisinde hayat bulduğu söylenebilir.

Kaplan, televizyonun çağdaş toplumlarda öykü anlatıcı olarak kültürel bir dışavurum arac1 olduğunu vurgulamaktadır (1992, s. 52). Televizyon yayıncılığı alanında günümüzde yapısal bir dönüşüme gidilerek kurmaca yapımlardan olgusal, gündelik hayattaki sıradan insanı konu alan reality yapımlara doğru bir dönüşüm yaşanmıştır. Ayrıca medya ve gerçeklik bağlantısı konusunda yapılan çalışmalar liberal çoğulcu toplum kuramındaki gerçekliğin yansıması kavramından Marksist eleştirel toplum kuramlarındaki gerçekliğin üretimi ve yeniden üretimine taşınmıştır. Bu alanda yapılan son çalışmalar ise toplumsal gerçekliğin inşa edildiğinden yola çıkarak bilginin çeşitli uzlaşımlara dayalı etkinlikler boyunca belirdiğini vurgulamaktadır (Dursun, 2013, s. 34-35). Kültürel çalışmalar perspektifi içerisinden kaynaklanan bu görüş toplumsal anlam ve gerçekliğin fenomenolojik süreçlerin ürünü olduğunu vurgulamaktadır. Reality programlar ve alt türleri 21. Yüzyılın başında dönemin sosyo-ekonomik ve kültürel yapısının bir ürünü olarak televizyon endüstrisi içerisinde ortaya çıkmıştır. Karmaşık ve çok yönlü bir sürecin ürünü olan reality programcılık anlayışının yaygınlık kazanmasındaki baskın etken ekonomik gelişmeler ve yayıncılık alanında yaşanan deregülasyon sürecidir. Özellikle geç kapitalist toplum yapısı içerisindeki neoliberal ekonomik girişimler ve medya tarafından yaygınlaştırılan tüketimcilik anlayışı bu televizyon türünün gelişmesini sağlamıştır. Eklektik anlatı yapısıyla reality programlar ulusal ve ulus ötesi toplumsal formlar içerisinde küresel, kozmopolit bir kültürün yaratılmasında aracı rol oynamaktadır (Lewis, 2010, s. 190-195; Deery, 2012, s. 2-3; Ganguly, 2012, s. 323, 342).

$\mathrm{Bu}$ çalışmada ulusal televizyon kanalları içerisinde reality programların alt türleri dikkate alınarak amaca yönelik bir örneklem oluşturulmuş ve bu yolla tespit edilen programların tüketim toplumu ve gösterinin ideolojik işleviyle ilişkisi, alana ait kuramsal bir çerçeve üzerinden nitel içerik analizi yöntemiyle analiz edilmiştir. 


\section{Kapitalizmin Gelişme Stratejilerinin Ürünü Olarak Tüketim Toplumu Kavramı}

Marksizm, ekonominin yanında toplumların ve tarihlerinin genel yapısını oluşturan sosyoloji ve siyaset gibi aktörleri de içerisine alan çözümleyici bir çerçeve sunmaktadır. Genel manada Marksizm, tarih kuramı veya tarihsel maddecilik olarak nitelendirilmektedir. Bu çerçeveler içerisinde, üretim biçimi "kölelik, feodalizm, kapitalizm", sınıflar "proleter, kapitalist" ve devlet gibi büyük kavramlar ortaya çıkmaktadır. Ayrıca her bir dönemin kendi sınıfsal yapısının bulunduğuna ve hâkim sınıfların güçlerini mutlak surette sergilediklerine dikkat çekilmektedir (Duménil ve Lévy, 2009, s. 11). Marksist bakış açısı kapitalizmin eleştirel bir gözle tarihsel bir perspektifte yorumlanmasını ön planda tutmaktadır. Harvey, tarihsel gelişim süreci içerisinde kapitalizmin dönemin üretim araçları ve ilişkileri bağlamında kendisini yeniden ürettiğini vurgulamaktadır. Buna göre içinde yaşanılan her dönem yeni bir düzenleme içerirken aynı zamanda kapitalist sistemin bizatihi devamlıllğı bağlamında bir süreklilik unsurunu da bünyesinde taşımaktadır (2010, s. 143-224). Marx, "Komünist Parti Manifestosu" adlı eserinde burjuva sınıfının varlığının üretim araçları ve üretim ilişkilerinin sürekli dönüşüme uğramasına bağlı olduğunu vurgulamaktadır. Katı olan her şey buharlaşıp havaya karışırken, kutsal olan her şey dünyevileşmektedir. Sonuçta ise insanlar yaşam koşullarının tüm çıplaklığı ile karşı karşıya gelmektedir (2013, s. 36). Giddens bu durumu kapitalizmin daha önceki sistemlerden daha akışkan bir yapıya sahip olmasına bağlamaktadır. Oluşan yeni durumda işgücünün çok daha kolay yer değiştirebilmesi ve farklı türlerde işlere daha kolay uyum sağlayabilmesi gerekmektedir (Giddens, 2016, s. 93). Kapitalizmin gelişim süreci içerisinde emek ve sermayenin esnekleşmesi süreci öne çıkmaktadır. Sanayi kapitalizmi döneminde kapitalistin sahip olduğu sermaye ve emek gücü genellikle bir coğrafi mekana bağlı olarak örgütlenirken, tüketim toplumunun işlerlik kazandığı 1970'li yıllarla birlikte bu alanlar mekânsal boyutta hareketlilik yetisi kazanmıştır.

Marksist bakış açısı kapitalizmde büyüme teorisini sermaye birikimi üzerinden açıklamaktadır. Birikimin artması kapitalist üretim tarzının büyümesini sağlarken sahip olduğu iç çelişkiler ve ortaya çıkan krizler ekonomik büyümenin devamlılı̆̆ını sağlamaktadır. 1970'li yıllarla birlikte birikim rejiminin değişmesi kapitalist sistemin yapısal özelliklerinden biri olarak öne çıkmaktadır. Buna göre sabit ve hareketsiz bir sermayenin oluşturduğu coğrafi bölge bu dönemle birlikte mekanın zaman tarafından imha edilmesiyle aşılmaya başlanmıştır. İnşa edilmiş çevredeki eski sermaye yatırımlarının değerini korumak ile birikim için yeni alanlar açmak için yapılan bu yatırımların yıkımı arasındaki hassas denge, sistemin devamlılığını sağlamaktadır. Ayrıca bu dönemle birlikte 1960'l yıllarda devamlı sermaye birikimi ve kapitalist sınıf iktidarının önünde engel olarak görülen işçi sınıfı da sermayenin daha ucuz ve uysal iş gücü talebi doğrultusunda göçün teşvik edilmesiyle küresel emek piyasasına ulaşımın yolu açılmıştır. Sermaye bu sayede o döneme kadar önem taşıyan sınıf dayanışmalarını parçalayarak hem üretim hem de tüketim alanında kullanılan yeni 
teknolojiler ile gündelik hayatın yapısal bir dönüşüm içine girmesini sağlamıştır (Harvey, 2012a, s. 287-289, 297-298; Harvey, 2012b, s. 23, 139). Douglas Dowd ise kapitalizmin 1970'li yıllarla birlikte yeni teknolojik olanaklar ve ulaşım sistemleriyle küreselleştiğini vurgularken toplumsal alanda ortaya çıkan tüketimcilik kavramının medya ile ilişkisine dikkat çekmektedir. Kitle iletişim araçları içerisinde özellikle reklam ve televizyon endüstrisi toplumsal alandaki kapitalist dönüşümün lokomotif gücü olarak belirirken öncelikle Amerika' da başlayan bu medya ekolojisi günümüzde tüm yerküre üzerinde etkili olmaya başlamıştır (2013, s. 249-252). Bu bağlamda 1970'li yıllar bir kırılma noktası olarak tarihe geçmiştir. Kapitalizm bu dönemde üretim düzeninden tüketim düzenine doğru geçiş yaparken, refah devleti uygulamalarının son bularak örgütsüz bir yapıya ulaşılması sonucunda kültürel alan genişleyerek tüm politik ve toplumsal alanı kapsamıştır. Oluşan yeni kültürel alan gösteri, eğlence ve tüketim ekonomisi üzerinden tanımlanır olmuştur.

Değişen piyasa koşullarında ve kapitalist ekonomik düzlemde sosyoloji dahil birçok disiplinin belirgin konularından biri tüketim merkezli gıdanın üretiminden pazarlanmasına kadar belirli süreçleri kapsayan beslenme davranışlarıdır. Besin ve yemek yeme çalışmalarının sosyolojideki hâkim eğilime dâhil edilmesini sağlayacak iki temel yol üzerinde durulmaktadır ${ }^{1}$. Gıdanın ekonomik ve kültürel boyutları tüketim toplumu içerisinde öne çıkarken ulaşım kolaylığı ile televizyon gündelik hayatın kapitalist dönüşümünde önemli işleve haizdir. Hem kapitalist üretim sürecinin sürdürülmesinde hem de tüketim nesnelerinin pazarlanmasında televizyon programları üzerinden toplumsal alana sunulan temsiller sistemin üretim ve yeniden üretim süreçlerinin işlerlik kazanmasını sağlamaktadır.

\section{Neoliberal Dönemde Gastronomi Kavramına Sosyolojik Bir Bakış}

Marksist bakış açısından yorumlandığında toplumsal olaylar diyalektik bir sürecin ürünüdür. Tarihsel materyalizm olarak da adlandırılan bu bakış açısından gastronomi kavramına yaklaşıldığında günümüzde neoliberal piyasa içerisinde şekillenen gastronomi alanının tarihsel süreçte farklı yaklaşımlarla ele alındığı görülmektedir.

Gastronomi tarihi üzerine çalışmaları olan Deniz Gürsoy’un, tarihçi Felipe FernandezArmesto' dan aktardığı ve insanlığın yemekle olan tarihsel evrimini içeren bilgiler, sekiz

\footnotetext{
1 İlki gıda üretim ve tüketiminin analizlerini içermektedir. Burada besinlerin paylaşım ve tüketim örüntülerinin, toplumsal farklılaşma boyutlarının (toplumsal cinsiyet, yaş ve sınıfın), gündelik yaşam deneyimlerindeki dışa vurulan alışkanlıklarının analizi bulunmaktadır. İkinci olarak ise gıda üretim ve dağıtım süreçlerinin analizlerinin son derece rasyonelleşmiş, sermaye yoğun ekonomik sistemlerinin işleyişini aydınlatmak için kullanılmasıdır. Besin alımı, vazgeçilmez fizyolojik bir gereksinim olmasına karşın, yemek yeme, temel fizyolojik boyutlarının ötesinde bir eylem olarak algılanmaktadır. Yemek yeme eyleminin bir dizi girift fizyolojik, psikolojik, ekolojik, ekonomik, siyasi, toplumsal ve kültürel süreçlerin kesiştiği bir noktada yer aldığı görülmektedir (Beardsworth ve Keil, 2011, s. 20-21).
} 
önemli devrimle bu alandaki sürekliliğin oluştuğunu göstermektedir². Yemeğin tarihsel süreç içerisinde hayatta kalmayı sağlayan fizyolojik bir ihtiyaçtan toplumsal bir olgu olarak ekonomik ve kültürel boyutlar kazanma süreci Marx ve Engels'in "Alman Ídeolojisi" adlı eserinde üzerinde önemli durduğu yeniden üretim kavramıla ilişki içindedir. Marx'a göre bir üretim tarzı sadece bireyin fiziksel varlığının yeniden üretimi olarak görülmemelidir. Daha çok bireylerin gerçekleştirildiği belirli bir faaliyet biçimi ve belirli bir yaşam tarzı olarak adlandırılmalıdır (2013, s. 30). Murat Belge, yemek yeme eyleminin insanoğlu için yaşamsal bir etkinlik olduğunu vurgulamaktadır. Dolayısıyla, yemeğin tarihinin incelenmesinin birçok bakımdan insanın tarihini incelemekle eşanlamlı bir uğraş olacağını savunmaktadır (2016, s. 33). Marx'ın işaret etmiş olduğu toplumsal ilişkiler süreci avcı-toplayıc1-tarım ve endüstri toplumları şeklinde süreklilik taşımaktadır. Bu sürece koşut olarak yemek yeme eylemi, duyusal ve kültürel etkileşimlerle, insanın hayatta kalmak için yapmak zorunda olduğu bir faaliyet olarak insanlık tarihini biçimlendirecek şekilde hayatın merkezine farklı formlarla taşınmıştır (Kanık, 2016, s. 9). Bu anlamda sürecin diyalektik olarak işlediği söylenebilir.

Sosyolojik ve antropolojik açıdan gastronomi kavramının dönüşümünde işlevselci, yapısalcı ve gelişimsel olmak üzere üç ayrı yaklaşım öne çıkmaktadır. İşlevselci yaklaşım toplumu biyolojik bir organizma şeklinde tasavvur etmiştir. Bir canlının hayatta kalması için işlevsel olarak farklılaşmış organlara ihtiyacı olması gibi toplumda işlevsel olarak farklılaşmış yapılardan oluşmaktadır. Bu farklılaşmış yapılara koşut olarak işlevselci görüş içerisinden besin ve yemek yeme davranışları üzerine bir dizi soru sorulmas ${ }^{3}$ mümkün olmuştur (Beardsworth, Keil, 2011, s. 100-103). Yapisalcı bakış Claude Lévi-Strauss tarafından ortaya konulmuştur. Bu yaklaşımın temel amacının toplumsal kurumların birbirine kenetlenen doğasını incelemek olduğu söylenmesine rağmen, araştırmacıların genellikle altta yatan kaideleri bulmaya çalışt1kları gözlemlenmiştir (Goody, 2013, s. 30-31). Gelişimsel yaklaşım Stephen Mennell tarafından geliştirilmiştir. Uygarlaşma sürecinin önemli etkilerinden biri bireylerin üzerindeki dışsal sınırlandırma uygulamalarının giderek içselleştirilmiş

2 Birinci devrim pişirmenin icadıdır. Yani ateştir. İnsanlığın bu icadı sayesinde diğer bütün canlılardan farklı bir konuma geldiği vurgulanır. İkinci devrim daha sosyal bir olgudur; yemeğin yalnızca yaşamı sürdürebilmek için zorunlu bir yakıt olarak algılanmayıp yemek yeme eyleminin sosyal bir olgu haline getirilerek içselleştirilmesi durumudur. Üçüncü devrim, hayvanların evcilleştirilmesidir. Dördüncü devrim tarımın başlaması olarak nitelendirilir. Beşinci devrim, yemeğin, sosyal farklılaşmanın bir aracı olma sürecine girmesi olarak değerlendirilirken; altıncı devrim, gıda maddelerinin uzun mesafeler kat edecek şekilde başka yerlere götürülmesiyle birlikte oluşan kültürel alışverişten doğan etkileşim ve değişim süreci olarak gösterilir. Yedinci devrimin ekolojik olduğu ileri sürülürken bu devrim sürecinin Amerika'nın keşfiyle başladığı bildirilmektedir. Son olarak sekizinci devrimin ise 19. yüzyılda başlayan ve günümüzde sürmekte olan, gıdanın endüstriyel bir ürün haline getirilmesidir (Gürsoy, 2018, s. 8).

3 Gıda üretimi, dağıtımı ve tüketimi gibi alt sistemler nasıl bir örgütlenme içerisinde bulunmaktadır ve bir bütün olarak işleyen sosyal sistemin devamını sağlamada ne gibi bir katkıları olmaktadır? Besinlerin temin edilme ve tüketim biçimlerinin toplumsal (besinsel olmayan) işlevleri nelerdir? Gizli işlevlerin yanında besin sistemi içerisindeki işlevsel olmayan olgular tanımlanabilir mi? İşlevsel olmayan unsurlar nasıl ortaya çıkmaktadır? Bir bütün olarak toplumsal sistem için bunların sonuçları nelerdir? (Beardsworth, Keil, 2011, s. 102-103). 
birtakım sınırlandırmalara yerini bırakmasıdır. Dışsal olandan içsel olana doğru gelişen değişim sürecinin, yemek yeme etkinlikleri de dâhil olmak üzere toplumsal hayattaki birçok alanı etkilediği vurgulanmaktadır (Beardsworth-Keil, 2011, s. 113). Mennel'in düşüncesi toplumsal modernleşme süreciyle ilişki içerisindedir. Batılı toplumlarda Aydınlanma Düşüncesi'yle başlayan toplumsal rasyonalizasyon süreci giderek modern ulus devlet yapısı altındaki bireyden neoliberal piyasa ekonomisi içerisinde sorumluluklarını eline alan bir özne kavramına geçiş yönündedir. Bu süreçte öznenin üzerindeki toplumsal kurumlar yoluyla gerçekleştirilen denetim mekanizmaları bir adım ileri giderek öznenin kendi kendisini denetlediği bir aşamaya yerini bırakmıştır. Michel Foucault oluşan yeni durumu yeni hakikat rejimi olarak adlandırmaktadır. Toplumsal yaşamda bilimsel bilgi, teknikler ve söylemler bireylerin gündelik hayatına sirayet ederek onu dönüştürmektedir (2006, s. 59-60). Bu anlamda tüketim toplumunda yeme-içme alanı bir özdenetim alanı olarak tanımlanabilir.

Antropolog Mary Douglas yemeğin biyolojik gerçekliğinin yanı sıra sosyal gerçeklikle de ilişkili olduğunu ileri sürmektedir. Bu bağlamda yemek bir koda dönüşürken kodladığı mesaj ortaya konulan sosyal ilişkiler örüntüsünde kendisine yer bulmaktadır (Goody, 2013, s. 46). "Deciphering a Meal" adlı makalesinde Douglas, yiyeceğin bir kod olarak ele alınması durumunda kodladığı mesajların sosyal ilişkiler örüntüsünde bulunduğunu vurgulamaktadır. Mesaj farklı hiyerarşilerde dahil etme ve dışlama rejimi şeklinde işlerken sosyal bileşenlere sahiptir. Buna göre bir dizi sosyal etkinlik farklı şekillerde kodlanabilmektedir (1972, s. 61-68). Mary Douglas tüketim antropolojisi üzerine çalışırken toplumsal alandaki kültürel simgelere odaklanarak bunların gündelik hayat içindeki işlevlerine açıklık kazandırmak istemiştir. Douglas'ın çalışmaları toplumsal sistem içerisinde gıdanın bir iletişim formu olarak bireylerle kurduğu ilişkiye odaklanmıştır.

Toplumsal yapıda kurumların, göstergelerin ve işaret sistemlerinin çöktüğü noktada anomik durumlar baş göstermektedir. Neoliberal ekonomik sistem toplumsal alandaki her türlü kurum, değer ve ilişki yapısını tek taraflı bir şekilde para ekonomisine bağlamıştır. Günümüzde yemeğin toplumsal düzenlenmesi en aza indirgenmiş̧ir. Bireyselleşmiş ve kutsallığından kopmuş bir yemek pratiği, gastro-anomi olarak kavramsallaştırılmaktadır. Geleneğin yönettiği bir toplumda, yeme alışkanlıkları içinde yaşanılan kozmosla uyumlu şekilde bir dizi kurala bağlıdır. Oysa çağımızda yemek gitgide bireysel bir etkinlik haline gelirken üst kuralları ve atıf noktalarını yitirmiştir (Fischler, 1980 ve Fischler, 2001'den akt. Akarçay, 2016, s. 66-67).

Neoliberal piyasa ekonomisi içerisinde yemeğin hazırlanmasından, sunulmasına ve tüketilmesine kadar olan süreç yeniden yapılandırılmıştır. Toplumsal alanda hızlı gelişme sürecinin bir parçası olarak ortaya çıkan anomi olgusunun gastronomi alanında işlerlik kazanmasında kozmopolit bir yaşam şekli ile yerel unsurların harmanlandığ 1 
Masterchef Türkiye ve The Taste Türkiye gibi reality yarışma programlarının etkisi bulunmaktadır. Bu programlar eklektik, yersiz-yurtsuz yeni bir kültürel alan yaratarak kültürün içerisindeki kod ve simgeleri yapıbozumuna uğratarak televizyonun soğuk ekranının arkasından kitleler ile paylaşmaktadır.

\section{Kültürel Alanda Gösteri Kavramı ve Kitle İletişim Aracı Olarak Televizyon}

Tarihsel olarak 1950'li yıllardan itibaren toplumsal alanda yaygınlık kazanan televizyon, ev içi "domestic" bir araç olarak kendisinden önceki radyo ve sinema gibi kitle iletişim araçlarının teknik ve anlatı özelliklerini bünyesinde taşıyıp onları özgün bir şekilde harmanlayarak yeni bir anlatı yapısı oluşturmuştur. Televizyonun teknik bir araç olarak gündelik hayat içerisindeki yaygınlı̆̆ ve içeriklerinin geniş kitlelerce takip edilmesi iletişim çalışmaları alanında dikkatin bu yana çevrilmesini sağlayarak televizyonun hem teknik olanaklarının hem de içerik bağlamında anlatı yapılarının analizini beraberinde getirmiştir.

Endüstri Devrimi'yle büyük kitlelerin kentsel alanda yaşamaya başlamasıyla birlikte daha önceki dönemlerde toprağa bağlı şekilde gelişen aristokrat kültür ve kırsal yaşamla özdeş tutulan halk kültürü ayrımları dışında yeni bir kültürel form oluşmaya başlamışııı. Kitle kültürü ya da kitle toplumu kavramsallaştırmasıyla anılan bu kültürel form televizyon çalışmaları içerisinde önemli bir yere sahiptir. Kitle kültürüne ilişkin yaklaşımlar temel olarak tutucu nitelikteki yaklaşımlar ve eleştirel yaklaşımlar olarak ikiye ayrılmaktadır. Tutucu nitelikli kitle kültürü yaklaşımını Alexis de Tocqueville, F. Nietzsche, T. S. Elliot, J. Stuart Mill ve Gustave Le Bon gibi kuramcılar dile getirmişlerdir". Kitle kültürüne eleştirel bir bakış açısıyla yaklaşan Frankfurt Okulu "Eleştirel Teori" olarak da adlandırılmaktadır. Bu teoriye göre ileri kapitalist toplumlarda kitle iletişim araçları birer kültür endüstrisi konumuna gelirken bunların ürettikleri kültür gerçek "otantik" değil, yapay "şeyleşmiş" bir kültür olarak tanımlanmaktadır. Bu alanda sanat özerkliğini yitirirken pazarlanabilir ve değiş tokuş edilebilir diğer tüketim mallarından fark1 kalmamıştır. Frankfurt Okulu'nun kitle kültürü eleştirisi esas olarak bu yapay kültürün toplumsal eşitsizliklerin sürdürülmesinde bir araç olarak egemen sınıflar tarafindan kullanılmasıdır. Kitle kültürünün başat biçimlerinin, yetkenci ideolojinin billurlaşmış görünümleri olduğunu söyleyen Frankfurt Okulu üyeleri bu kültürün kapalı ve durağan bir yapıya sahip olduğunu vurgulamaktadır (Mutlu, 1991, s. 19-21).

4 Bu kuramcılar kitle sözcüğünün oldukça olumsuz bir anlam taşıdığını belirterek, kitlenin bireyin toplumsal yaşamdaki varoluşuna engel koyan, düşük beğeni düzeyleriyle aristokrat kültürün aşınmasına neden olan ahlaki ve sanatsal anlamda yoksun bir grup olduğunu belirterek eleştirmişlerdir (Çakır, 2014, s. 222-234).

5 Frankfurt Okulu, temeli 1930'larda Avrupa'da atılmıştır. Okulun önde gelen temsilcileri arasında Thedor W. Adorno, Max Horkheimer, Herbert Marcuse, Leo Lowenthal ve Eric Fromm bulunmaktadır. Frankfurt Okulu'nun çalışmaları üç ana tema üzerinden gerçekleşmektedir: sosyal bilimlerdeki pozitivizmin epistemolojik ve metodolojik eleştirisi, teknokratik-bürokratik yeni bir egemenlik biçiminin oluşumunda temel bir etmen olarak bilim ve teknolojinin ideolojik etkisine yönelik eleştirel bir tavır ve kültür endüstrisi boyutlarının çözümlenmesi (Bottomore, 2013, s. 34,56,62). 
Frankfurt Okulu bünyesinde yürütülen çalışmalar film ve televizyon endüstrisi alanındaki eleştirel çalışmalara çeşitli şekilde etki etmiştir. Ancak okulun üyelerince geliştirilen kültür eleştirisi ve kültür endüstrisi incelemeleri içinde televizyon endüstrisi, televizyon programları ya da aracin toplumsal etkileri konusuna pek fazla yer açılamamıştır. Bu durumun nedeni okulun ilk iki döneminin ${ }^{6}$ televizyonun kitlesel kullanımının yaygınlaştığı ve toplumsal etkilerinin tartışıldığı bir dönemle çakışmamış olmasıdır. Frankfurt Okulu'nun özellikle ilk iki dönemi üyelerinin televizyonun yaygın olarak kullanıldığ 1 tarihsel döneme denk gelmemelerine rağmen görsel iletişim alanına ait görüşleri Marksist bir bakış açısı içerisinden yorumlanabilir. Tecimsel bir etkinlik olarak kitle iletişim alanı her zaman dönemin egemen güç odaklarıyla yakın ilişki içinde olmuştur. Üretim araçlarının sahipliğinde olduğu gibi kitle iletişim araçlarının sahipliği ve yönetimi konusunda toplumdaki küçük bir ayrıcalıklı grup söz sahibidir. Televizyon tecimsel bir araç olarak reklam gelirlerine muhtaçtır. Bundan dolayı kapitalist sistemin egemen değerleri ve mesajları televizyonun anlatı yapısı içerisinde doğallaşarak geniş kitlelerle buluşmaktadır.

Genelde kitle iletişim özelde ise televizyon eleştirisi alanında yapısal dönüşüm İngiliz Kültürel Çallşmalar Okulu'nun çalışmalarıyla başlamıştır?. Kültürel çalışmalar içerisinde televizyon metinlerinin incelenmesinde yapısalcı yaklaşımlar ile birlikte izleyicilerin anlamlandırma pratiklerini temel alan yaklaşımlar ön plana çıkmaktadır. Fiske’ye göre, televizyon endüstrisi bir meta olarak program üretir ancak bu kültürel meta herhangi bir maddi nesne değildir. Ekonomik işlevi satıldığı anda sona ermeyerek reklamcılar için satılan izler kitleyi üretmektedir. Popüler kültür, endüstrileşmiş bir kültür olarak birbirleriyle çelişkili birçok mesajı içinde taşımaktadır. Bir yandan ürün toplumsal farklılıkları reddedip insanların ortak paydalarına seslenirken diğer yandan farklı toplumsal sınıflar, kimlikler ve cinsiyetler kendi gereksinimlerine göre kültürel metayı bir kaynağa dönüştürerek kendi kültürel gereksinimlerini gidermektedir. Böylece tüm popüler kültür alanı toplumsal deneyimin anlamları, bireyin kişiliği ile toplumsal düzen arasındaki ilişki ve bu düzenin metinleri ile metaları üzerine bir mücadele sürecidir (1996, s. 39-41).

Popüler kültür içerisinde televizyon eğlendirici bir araç olmasının ötesinde eğlenmeyi her türlü deneyimin temsilinin genel çerçevesi haline getirmiştir. Bütün temalar eğlence

6 Frankfurt Sosyal Araştırmalar Enstitüsü'nün 1923'te kuruluşundan 1933 yılında ABD'ye taşınmasına kadar olan Almanya'daki etkinlik dönemi 1. Dönem, 1950'de yeniden Frankfurt'a taşınmaya kadar geçen dönem 2. Dönem, 1950-1970 yılları arası 3. Dönem ve 1970’ten Habermas'ın yakın zamanlara kadar olan çalışmalarını kapsayan zaman dilimi 4. Dönem olarak adlandırılır. Ayrıntılı bilgi için bknz. Tom Bottomore Frankfurt Okulu ve Eleştirisi

7 Britanya Kültürel Çalışmaları olarak bilinen alan, çağdaş kültürel kuram içerisinde önemli bir yere sahiptir. Alanın kökenleri 1950'lerin sonları ve 1960'ların başlarında yazın eleştirmenleri olan Richard Hoggart ve Raymond Williams'ın çalışmalarıyla başlamaktadır. Bu alandaki çalışmalar 1960'ların sonları ve 1970'ler boyunca neo-Marksist düşünürlerce ilerletilmiştir. Kitle iletişim araçlarının metinsel incelemeleri, bunların hegemonya ve ideolojiyi yeniden üretmedeki işlevleri, gündelik hayat içerisindeki özellikle alt kültürlerin etnografik incelemeleri ve popüler kültür, kültürel çalışmaların başlıca ilgi alanlarını oluşturmaktadır (Smith, 2005, s. 208-213). 
olarak sunulurken eğlence bir anlamda televizyondaki her türlü söylemin üst-ideolojisi haline gelmektedir. Sonuçta televizyon dezenformasyon denilebilecek bir enformasyon türü yaratarak bilgilenme anlamında değişiklik yapmaktadır (Postman, 2004, s. 101-102, 121). Bilgi "information" ile eğlence "entertainment" içeriklerinin birleşmesi sonucunda bilgi-eğlence "infotainment" formatı televizyonun başat anlatı yapısı haline gelmiştir. Debord, modern toplumların ayırt edici yönünün gösterinin sürekliliği olduğunu vurgulamaktadır. Bunun nedeni ise gösterinin tahakkümünün, kendi yasalarına tabi olan bir kuşağı yetiştirebilmiş olmasıdır. Günümüzde gösteri bütünleşmiş bir hâl alarak gerçekliği yeniden oluşturmakta ve onun tamamına nüfuz etmektedir (2006, s. 178-180). Baudrillard'a göre ise bu toplumsal yapıda gerçeklik ilkesi teknik araçlar tarafindan üretilmektedir. Gerçekliğin diğer yarısı olarak nitelendirilebilecek olan düşsel bu aşamada ortadan kalkarken yerini bütünsel gerçeklik olarak adlandırılabilecek bir yapıya bırakmaktadır (2005, s. 13-16). Televizyon aracı bu anlamda her türlü içeriği eğlence temasıyla birleştirirken toplumsal gerçekliği ise bütünlemiş bir gösteri teması altında bir araya getirmektedir. Televizyon sonuçta gerçekliğin tamamen teknik olarak üretildiği bir evrende referans noktalarından yoksun görünümleri dolaşıma sokan ve toplumsal ötesi bir yaşamdan fragmanlar sunan teknik bir araç haline gelmiştir.

\section{Reality Yarışma Programlarında Gösterinin Toplumsal İşlevi Bağlamında Gastronominin Değiş̧en Doğası}

Televizyon bilgilendirici ve eğlendirici içerikleri kendi bünyesinde barındırırken bunu belli bir öyküleme yani anlatım tekniği kullanarak gerçekleştirmektedir. Çağdaş toplumlardaki en önemli öykü anlatma aracı olan televizyon sadece dizi ve seriyaller gibi kurmacaya dayalı "fictional" program türlerinde değil; aynı zamanda haberler, spor ve bilim programları gibi sözde gerçek olaya dayalı "factual" program türlerinde de bu işlevi yerine getirmektedir (Kaplan, 1992, s. 51-52, 75). Toplumsal alanda gerçek ve doğru hakkındaki fikirlerimiz bir sıra deneyime dayanmaktadır ${ }^{8}$. Modern toplumlarda bu alanda kitle iletişim araçlarının yönlendirici etkisi bulunmaktadır. Jacques Ellul'e göre ise görmeye "vizüel" dayalı olan diyalektik olamaz, diyalektik dile dayalı bir düşünce sistemidir. Görmeye dayalı olan ise çizgisel ve mantıksal zorunluluğun bilgisidir. Görülen şey inşa edilen şeydir ${ }^{9}(1998$, s. 26). Televizyonun temsil etme ve inşa süreci reality programlar gibi olgusal içeriklere dayalı yapımlarda belirgin olarak

8 Bunlardan ilki kültürel deneyimdir. İnsanlar yaşamları boyunca kültürün gerçek olarak gördüğü şeyleri öğrenirler ve kullanırlar. Kültür içerisindeki yetiştirme biçimleri gerçekliğin çeşitli tarzlarının kurallarını öğrenmemizi sağlamaktadır. İkinci deneyim şekli gerçek yaşamdır. Yani insanın yaşam deneyimi gerçekliği tanımlamasında önemli bir yer kaplamaktadır. Bir başka deneyim şekli ise medyanın kendisidir. Gerçeklik günümüzde medyanın içine dokunmuştur. Medya belirli insanların niçin belirli kategorilere dahil olması gerektiğine dair anlayışı düzenler. İnsanların hikaye edici tarz içerisinde medyada temsil edilmesi bu algısal kümelerin inşa edilmesini ve sürdürülmesini sağlamaktadır (Burton, 1995, s. 111, 123-124).

9 Ellul, eskiden imajlara sadece seçkin bir azınlığın ilgi gösterdiğini vurgulayarak günümüzde geniş bir kitlenin imajlarla iç içe yaşadığını vurgulamaktadır. Bu toplumsal yapıda temsil "representation" zihinsel çerçevemiz olarak iş görmeye başlamaktadır. Bu bağlamda bir audio-visual (işitsel-görsel) ya da ideo-visual (düşünselgörsel) uygarlığa girildiği düşüncesi yanlıştır. Aksine görsel gürültü uygarlığına girildiği söylenebilir. Gürültüye yapılan aşırı vurgudan dolayı gürültü-görsel evren içinde yaşadığımız söylenebilir (1998, s. 170). 
öne çıkmaktadır. İçinde yaşanılan toplumsal yaşamla bir çeşit ilişki ve iletişim kurma şekli olan reality yayınc1lık konusunda Robins, "neo-televizyon" ya da "realitytelevizyonu" olarak adlandırılan program türünün bireylerin postmodern kentle aralarında görsel bağ kurdukları, bir deneyimde bulunarak o deneyimin içinde kayboldukları kamusal eğlence çeşidi olduğunu vurgulamaktadır (1999, s. 223). Reality programlar bu anlamda sadece bir televizyon program türü olmanın ötesinde içinde yaşanılan sosyo-ekonomik ve kültürel yapıyla ilişkili toplumsal bir fenomen olarak adlandırılabilir.

Televizyon yayıncılığı alanında 2000'li yıllarla birlikte gerek program yapım sürecindeki teknik gelişmeler gerekse farklı formatların melezlenerek "hybrid" format çeşitliliğinin artırılması sayesinde bir yön değişikliği yaşanmıştır (Kaya, 2011, s. 115). Reality televizyon programlarının teknik olanaklarının ve anlatı yapısının melez doğası günümüzde küresel çapta dolaşımda olan kozmopolit yaşam şekilleriyle uyum içerisindedir. Hill, reality programları televizyon dizileri gibi kurmaca ya da haberler gibi gerçek hayata ilişkin program türlerinden ayırt edici özelliğin yazılı bir metne bağlı olmaksızın dramatik ya da komik durumları sunması ve gerçek olayları belgelemesi olduğunu vurgulamaktadır (2005, s. 44). Ayrıca ekonomi-politik manada reality program katılımcıları, doğal olarak kullanılan ve atılan bir işgücü olarak öne çıkmaktadır. Mark Andrejevic, reality program türünün ayırt edici yönünün profesyonel bir aktör ya da şovmen olmaksızın reality programına yani bir "gerçeklik şovuna" herkesin katılabilmesi olduğunu belirtmiştir (2004, s. 6). Ayrıca reality televizyonu yapımcıları eğlenceli katılımcıları yan ürün "spin-off" olarak başka programlar içerisinde sunarak katılımcıları düzenli olarak geri dönüştürmektedir. Sıradan insan, yarışma programları, docudrama, reality programları içerisinde yapımcıların büyümelerini ve pazarı kontrol etmelerini sağlamaktadır (Curnutt, 2016, s. 145). Bu anlamda reality programları televizyon endüstrisi içerisinde üretim maliyetlerinin sınırlı olduğu, yıldız oyuncular yerine sıradan insanın iş gücü olarak sistem içerisinde kullanıldığı yeni bir dönemi nitelemektedir.

Annette Hill, 1990'larla birlikte reality programcılığında üç ana tür olduğunu belirtmektedir. Bunlar: suç ve acil servis programları, dizi belgeselciliği (docu-soap) ve yaşam tarzı (lifestyle) programları, reality yarışma programları olarak sıralanmaktadır. $\mathrm{Bu}$ çalışmanın konusunu oluşturan Masterchef Türkiye ve The Taste Türkiye reality yarışma programları melez bir anlatı içerisinde yaşam tarzı programlarıyla yarışma programlarının belirli özelliklerinin karışımından oluşmaktadır ${ }^{10}$.

Televizyondaki gastronomi programları reality program formatının bir parçasıdır. Kimi zaman kamusal alandaki bir kişilikle keyifli bir söyleşi eşliğinde şefin yaptığı yemeklerin tadılması ya da yarışma formatı içerisinde televizyon şefi "Television Chef"

10 Yaşam tarzı programları 1990'ların sonlarında İngiltere'de prime time yayıncılığında geniş bir izleyici kitlesine ulaşmıştır. Tüketim toplumu değerlerinin medya dolayımıyla izleyiciye aktarıldığı bu program formatı yemek hazırlama, ev dekorasyonu, estetik müdahaleler gibi konuları içermektedir. Reality yarışma programları ise katılımcıların duygusal bir gerilim içinde psikolojik ya da güce dayalı oyunlarda yeteneklerini gösterdikleri televizyon formatıdır (Hill, 2005, s. 24, 27, 31). 
kavramı yeni bir olgu değildir ${ }^{11}$. Televizyon şefleri gerek kendi başlarına program yaptıklarında gerekse bir yarışma programı içerisinde jüri olarak görev aldıklarında televizyon kişiliği haline gelmektedirler. Bu programlarda kapitalist sistemin üretim ve tüketim alanlarının tümü koordine edilmiş bir şekilde birlikte çalışmaktadır. Yemek yapımında kullanılacak olan hammaddenin, yiyeceğin hazırlanması için gerekli olan mutfak eşyalarının üretilmesi, gastronomi bilgisinin bir uzmanlık alanı olarak kitaplar, dergiler ile yayılması, gündelik yaşamın rutininin dışına çıkma amacıyla ya da toplumsal alanda dolaşımda olan güncel tarzların ve anlamların sembolik tüketiminde bu programlar işleve sahiptir. Reality televizyonu, yarışmacıların ve izleyicilerin katılımı için fırsatlar yaratırken hikaye edici bir anlatı içerisinde insanın özgünlügü ile emtia ilişkileri arasında dramatik bir arka fonda işlev görmektedir (Bowrey, 2013, s. 73). Bu açıdan yaklaşıldığında gastronomi ile televizyon yayıncılığının kesişim alanının çok katmanlı toplumsal bir anlama sahip olduğu görülmektedir.

Modern yaşamın her alanını kapsayan uzmanlaşma eğilimi kitle iletişim alanını da etkisi altına alarak dönüştürmüş̧ür. Burada öne çıkan kavram tematik televizyon yayıncılığıdır. Popüler kanallar olarak adlandırılabilecek büyük kanalların programlarının, magazinleşme, reklam baskısı ve reyting savaşları arasında içeriksizleşmesi izleyicinin tematik kanallara yönelmesini beraberinde getirmiş̧ir. Bunun yanında tematik kanallara talep artışının diğer bir nedeni ise teknolojideki gelişmelerden ötürü maliyetlerin düşmesidir. Günümüzde tematik yayıncıllk yapan kanalların birçoğu reality program içeriğine sahiptir. Örneğin mutfak televizyonu, ağ sonrası dönemde niş programla, küçük homojen izleyiciler, doğrusal olmayan izleme pratikleri ve çok kanallı yapının bir ürünüdür (Curnutt, 2016, s. 144).

Gastronomi programları ve medya arasındaki ilişkiler bağlamında öne çıkan bir diğer konu şeflerin mesleki ve kültürel birikimlerini ne derece ekranda yansitmaları gerektiğine ilişkin tartışmalardır. Televizyonda mutfak prestijini ekonomik zenginliğe yöneltmek için bir baskı söz konusudur. Ancak şef, ekonomik kar arzusu ile kendi uzmanlık alanı içerisinden çok fazla bilgi sunarsa bu durum kültürel bir yetkisizliğe yol açabilmektedir. Şefin becerileri, hayal gücü ve en iyi şeflere mutfak alanında meşruiyetlerini veren sanatsal yaklaşımı kitle zevklerine satıldığında şefler meşruiyetlerini kaybetme ile karşı karşıya kalmaktadırlar (Ashley ve arkadaşları, 2004, s. 179). Bu durumda popüler eğlence içeriklerinde şeflerin kendi uzmanlık bilgilerinin sunumuyla bu yetkinliğin kamusal alanda paylaşımı sonucu yaşanabilecek mağduriyet arasında gerilim yaşadıkları söylenebilir.

11 İngiliz televizyonunda yemek pişirme programları ilk kez 1930'larda başlamıştır. 1950'lerde Phillip Harben ilk tam teşekküllü televizyon şefi olarak kendine has özellikleriyle kendisinden sonra gelen ünlü şeflerle birtakım özellikleri paylaşır: ilk olarak kendisine özgü bir tarzı bulunmaktadır, daha sonraki bazı şefler gibi televizyon ünlüsü olarak bir takım hafif eğlence formatlarında yer almışır, bir dizi yemek kitabı yazmakla beraber "Harbenware" adlı yapışmaz tavayı piyasaya sürmüştür. Son olarak ise yemek bilgisinin genişlemesi, uluslararası yemek sunumları, dondurulmuş gıda gibi yeni bileşenleri mutfakta kullanması gibi konularda öncü olmuştur (Ashley, Hollows, Jones ve Taylor, 2004, 173). 
Finkelstein, yemek ve eğlence kavramlarının bileşiminden "foodatainment" beslence kavramını türetmiştir. 20. Yüzyılın sonuyla birlikte gıdanın tüketim toplumunda yazılı basın ve televizyon üzerinden sunum şekli ve temsili işlevsel bir hale gelerek, moda ve eğlence endüstrisiyle eklemlenmiştir (1999, s. 130). Televizyonun kültürel bir form olarak içerisine aldığı her kavramı eğlence ve izlenebilir olma teması içerisinden sunduğu görülmektedir. Bunun nedeni tecimsel bir yapı olan televizyonun reklam gelirlerini arttırma ve daha çok izleyiciye ulaşma isteğidir. Bu bağlamda tüketim toplumunda gastronomi alanı da gösteri teması altında kapitalist sistemin saiklerine göre yeniden üretilerek toplumsal dolaşıma sokulmaktadır denilebilir.

\section{Yöntem}

Çalışmada, günümüzde televizyon dolayımıyla şekillenen modern toplumların gündelik yaşamı içerisinde öne çıkan gastronomi alanının tüketim kültürü ve kapitalist sistem içerisindeki yeri ve anlamı medya etkileşiminde eleştirel bir bakış açısıyla incelenmiştir.

Neoliberal piyasa ekonomisi içerisinde sistemin sürdürülmesi ve yeniden üretiminde işlevsel bir alan olan gastronominin, reality programlar üzerinden hangi şekillerde dolaşıma girdiğinin ve bu programların toplumsal bir fenomen olarak işlevlerinin saptanması çalışmanın temel araştırma sorunsalını oluşturmaktadır. Konu ulusal kanallar üzerinden incelenmiş araştırmanın problemine zengin bilgi kaynağ1 oluşturabileceği düşünüldüğ ü için ve birçok nitel araştırmada tercih edilen amaca yönelik bir örneklem üzerinden çalışmanın yapıldığ 04.11.2019-17.11.2019 tarihleri arasında konuyla ilgili uluslararası formattaki gastronomi yarışma programlar1 ${ }^{12}$ incelenmiştir. Ele alınan programlar şunlardır: MasterChef Türkiye (TV 8), The Taste Türkiye (Fox TV).

Çalışmada toplamda 24 saatlik görüntü nitel içerik analizi yöntemiyle ${ }^{13}$ analiz edilmiştir. İçerik analizi yönteminde araştırmanın temel sorunsalı ve örneklemi belirlendikten sonra üçüncü aşamada analiz birimlerini oluşturacak kategorilerin belirlenmesi gelmektedir. Kategorilerin oluşturulmasında temel olarak iki yaklaşım söz konusudur. Birinci yaklaşım, araştırmada ele alınan kuramsal çerçeve üzerinden analiz

12 Her iki yarışma programının Türkiye’deki ikinci sezonu çalışmada ele alınmıştır. MasterChef jüri üyeleri Mehmet Yalçınkaya, Somer Sivrioğlu ve İtalyan şef Danilo Zanna'dır. The Taste Türkiye jüri üyeleri Ali Ronay, Esen Hünal ve Rafet İnce'dir. Programın sunuculuğunu MasterChef eski jürisi Hazer Amani yapmaktadır. Fox TV'de yayınlanan The Taste Türkiye programı reytinglerinin düşük olması nedeniyle 18 Kasım 2019 tarihinde final yapmıştır.

13 Sosyal bilimler alanında pozitivizm sonrası metodolojik ve yöntem bilimsel çalışmalar nicel çalışmalardan nitel çalışmalara doğru bir gelişme göstermektedir. Sosyal gerçekliğin birden çok boyutu olduğu varsay1mından yola çıkarak bütüncül (holistik) bir yaklaşım izleyen nitel çalışmaların bilimsel literatüre katkısı araştırma sonuçlarının ileride yapılacak çalışmalar için birer veri olarak genelleme yapılabilmesidir. Burada kastedilen genelleme türü istatistiksel bir genelleme değil analitik bir genelleme şeklidir. Nitel içerik analizi geniş medya içeriklerinin kuramsal bir perspektif etrafında çalışılmasına olanak vermektedir (Yıldırım ve Şimşek, 2000: 208-209). 
kategorilerinin oluşturulmasıdır. İkinci yaklaşımda kategoriler önceden saptanmamıştır. Mesaj öğeleri incelendikten sonra kategoriler belirlenmektedir (Bilgin, 2006, s. 11-14; Gökçe, 2006, s. 57-60). Bu çalışmada ilk yaklaşım benimsenerek kuramsal olarak oluşturulan çerçevenin içerisinden oluşturulan kategoriler üzerinden programlarda öne çıkan temalar incelenmektedir. Böylelikle kuramsal düzlemde verilen bilgiler ışığında gastronomi yarışma programları yorumlanarak bu programların kapitalist sistem içerisinde yeri ortaya konulmaya çalışılmaktadır. Araştırmanın kısıtlılıklarını; elde edilen sonuçların programların 15 günlük sayısı ile sınırlı olması oluşturmaktadır.

\section{Araştırma Bulguları ve Yorumlar: Tüketim Toplumu Değerlerinin Sunulduğu Bir Mecra Olarak Gastronomi Yarışma Programları ve İdeolojik Analizi}

Neoliberal ekonomik sistem içerisinde kazançlı ve güncel bir alan olan gastronomi alanıyla televizyon yayıncılığının kesişim noktasında bulunan gastronomi temalı reality yarışma programlarının kapitalist sistem içerisindeki yeri ve rolünü irdelemek amacında olan bu çalışmada programlar Niteliksel İçerik Analizi yöntemiyle incelenmiştir. Araştırma bulgularının kodlanması aşamasında yöntem kısmında değinildiği gibi kuramsal çerçeveye koşut olarak bir kategorik ayrım oluşturulmuştur ${ }^{14}$.

Analizde ele alınan ilk kategori genelde televizyonun özelde ise reality programcilık şeklinin yapısal bileşenleri üzerinden ele alınan programların incelenmesidir. Masterchef Türkiye ve The Taste Türkiye programları uluslararası formattaki gastronomi alanına ait reality yarışma programlarıdır. Televizyonun anlatı yapısında değinildiği gibi tüm televizyon program türleri belirli bir hikaye edici tarz içerisinde anlatı yapılarını oluşturmaktadır. Modern toplumların gündelik hayat etkinlikleri içerisinde kitleler bu teknik aracın anlattığı öyküleri dinleyerek içinde yaşadıkları toplumu yorumlamaya çalışmaktadır. Televizyonun gerek kurmaca gerekse olgusal içeriklerinde öykü anlatması aynı zamanda sunulan yapımların merak öğesi, geciktirme, gerilim oluşturma gibi bir takım dramatik unsurları bünyelerinde taşımaları anlamına gelmektedir. Reality programlar, gerçek hayattan alınmış olgusal içeriklerine rağmen kurmaca bir anlatıya sahiptir. Masterchef Türkiye ve The Taste Türkiye programları incelendiği zaman yarışmanın içerisinde kullanılan dramatik unsurların yardımıyla izlenilebilir olmayı arttırmayı amaçladıkları görülmektedir. Bu dramatik etki kimi zaman verilen görevin "yemek yapımı" yerine getirilmesi sürecinde yaşanan aksaklıklar ile oluşan geciktirme unsuruyla kimi zaman şeflerin yemek yapım sürecinde ya da değerlendirme aşamasındaki yorumlarıyla yükselen gerilimle, kimi zaman ise sonuçta iyi bir tabağın ortaya çıkarılması sonucu oluşan rahatlama ve katharsis anlarıyla işlerlik kazanmaktadır.

14 Oluşturulan kategoriler şunlardır: reality televizyonculuk şeklinin yapısal bileşenleri olan kurmaca ve olgusal ayrımının işlerliğini sağlayan dramatik anlatı yapısı, televizyon anlatısında bir üst dil olarak ortaya çıkan eğlence kavramı ve televizyonun kapitalist toplum içerisindeki ideolojik konumu; tüketim toplumunun işlerliğini sağlayan uzman bilgisi, yaşam tarzları, gösteri teması ve postmodern kültür. 
Dramatik etkiyi güçlendiren unsurlardan biri de tıpkı bir kurmaca yapıttaki gibi program içerisinde işlerlik kazanan karakterizasyondur. Örneğin Masterchef Türkiye jüri üyelerinin her birinin farklı kişilik özellikleri bulunmaktadır. Mehmet Yalçınkaya, diğer şeflere göre daha otoriter bir figür olarak yarışmacıların eksik yönlerinin ortaya konulup törpülenmesinden sorumludur. Somer Sivrioğlu, Yalçınkaya'nın aksine daha olumlu ve esprilidir. Genelde dünya mutfaklarından örnekler vererek yarışmanın uluslararası formatı içerisinde kozmopolit bir karakter olarak öne çıkmaktadır. Danilo Zanna ise jüri üyeleri içerisindeki en sempatik ve yapıcı yüzdür. İtalyan olan Zanna televizyon anlatısı içerisinde stereotipik bir temsil olarak öne çıkmaktadır. Eğlenceli ve hareketli tarzıyla tipik bir Akdenizli olan Zanna bozuk Türkçesiyle program açı1ışlarında "hepize hoşgeldiniz" demektedir.

Benzer şekilde yarışmacılar da farklı karakterlerde kişiliklerden oluşmaktadır. Masterchef Türkiye'de program analizlerinin yapıldığ 1 dönemde Yasin $\mathrm{Obuz}^{15}$ adlı yarışmacı davranışları ve konuşmasıyla dikkat çekmektedir. "Klsmetse Olur" programında düzgün konuşmasıyla bilinen Yasin Obuz MasterChef Türkiye yarışmasında farklı şive ve anlaşılmayan konuşmasıyla öne çıkmaktadır ${ }^{16}$. Yasin Obuz incelendiğinde televizyon endüstrisi için iki önemli nokta öne çıkmaktadır. İlk olarak değinildiği gibi dramatik bir anlatı oluşturmak amacıyla ilginç karakterlere programlarda yer verilmektedir. Özellikle reality programlar gündelik yaşamın sıradanlığı içerisinde çoğunlukla gözden kaçan tuhaflıkları ve gariplikleri ekrana getirmektedir. Bunun içerisinde sistem tarafından yaratılmış yapay tuhaflıklar da söz konusudur. Simmel bu durumu modern kültürün hüküm sürdüğü kentsel yaşamın belirleyici bir özelliği olarak tanımlamaktadır. Kentsel yaşamın bireyselleşme yönünde eğilimi sonucunda bir yandan heterojen bir topluluk içerisinde kaybolma öne çıkarken diğer yandan insan, kasıtlı bir şekilde tuhaf olmaya teşvik edilmektedir. Yapmacık tavırlar, ani değişiklikler yoluyla farklı olma ve diğerleri arasından sivrilme yeni varoluş formlarıdır (2011, s. 99). İkinci olarak kuramsal kısımda bahsedildiği gibi televizyon endüstrisi yan ürün "spin-off" olarak adlandırılan karakterler yoluyla izleyicinin dikkatini farklı programlara çekmeye çalışmaktadır. Obuz, reality programlar içerisinde ilgi çekici bir karakter olarak birden fazla programda yer almıştır. Profesyonel olarak gastronomi bilgisi ve bu alana ait ilgisi olmamasına rağmen araçsal bir konumda söz konusu programda kullanılarak en

15 Yasin Obuz, daha önce farklı bir kanalda yayınlanan Klsmetse Olur adlı reality formatındaki evlenme programına katılmıştır. Masterchef Türkiye programında ise yarışmacı şef konumundadır. Bu programdan elendikten sonra aynı kanalın farklı bir reality yarışma programı olan Survivor'da gönüllüler takımında yer almaktadır.

16 Yarışma boyunca şu sözleri dikkat çekicidir. Kusura bakma Suna ben senin takımına gelmek istemem açıkçası. Elektrik negatif aldığım yerde ben durmam arkadaş. Ben pozitif bir adamım. Çünkü senin takımın ego kokar yani bildiğin bütün egoları toplamışın yani. Ben gelmem senin takımına. Neden, rahat olduğu yerde yarışmak isterim anlatabildim? Gelmek istemezdi king... (Der ama yine Suna'nın kaptanı olduğu mavi takıma gider).

(Gözlerinde güneş gözlüğü, başında şapka, ellerinde eldiven ve firça) Bugün tarihi bir gün nasıl diyeceksin? Çünkü müfettiş geçit hırşit, yapılan manipülasyon ve şikeyi buldu tek başıma ortaya çıkattım. Buda müfettiş hırşit geçit'in tarzı. BUUUUUMMM! 
yüksek izleyici kitlesine ulaşılmaya çalışılmıştır. Bu durumun nedeni ise televizyonun tecimsel bir araç olarak reklam gelirlerine ihtiyaç duymasıdır.

Andrew Wernick, modern toplumlardaki medyanın önemine dikkat çekerek bu süreci promosyon kültürü olarak adlandırmıştır. Bu kavram televizyondaki programların, reklamların ve güncel olayların birbirine gönderme yaptığı bir alanı vurgulamaktadır. Gündelik hayat içerisinde televizyon başta olmak üzere medya ürünlerinin oluşturduğu sembolik evren içerisinde metinlerarasılıklar "Intertextuality" kurularak, anlam toplumsal dolaşıma sokulmaktadır (1991). Masterchef Türkiye programı jüri üyelerinden Danilo Zanna, gıda endüstrisinde hizmet veren firmalardan biri olan Pınar markası için hem "Pınar Labne" adlı reklam kampanyasında rol almış hem de Masterchef Türkiye programından etkilenerek hazırlanmış olan "Pınar Chef" yarışmasında moderatör olarak görev yapmışıır ${ }^{17}$. Ünlü şefin farklı medya içerikleri içerisinde yer alması medyadaki metinlerarasılık kavramının ve promosyon kültürünün bir örneğini teşkil etmektedir.

Masterchef Türkiye ve The Taste Türkiye programlarında televizyon endüstrisi açısından öne çıkan bir diğer unsur ürün yerleştirme ya da doğrudan reklamcılık faaliyetidir. Program içerisinde şefler kimi zaman reklama geçilmeden önce ya da yemek yapımının en heyecanlı anında araya girerek herhangi bir tüketim ürününün tanıtımını yapmaktadır. Tanıtımı yapılan ürünler arasında mutfakta kullanılan yemek malzemeleri bulunmaktadır. Reality televizyonu melez bir programcılık şekli olarak reklam endüstrisiyle yakından ilişki içindedir. Ürün yerleştirme, sponsorluk ve ortak yapım gibi teknikler ile reklamcılık eğlence temasıyla bir araya getirilmektedir. Reality programların, senaryosuz, gerçek yaşamı yansıttığı iddiası bu yeni türün ticari manipülasyonuna izin vermiştir (Deery, 2004, s. 1-3, 18). Görüldüğü üzere son yıllarda reality programlar reklam endüstrisi için gerek gerçek insanları satış stratejisinde kullanabilmeleri gerekse eğlence içeriği ile gündelik hayatı bir araya getirebilmeleri nedeniyle önemli bir alan olarak öne çıkmaktadır.

Kapitalist sistem hem tüketim ilişkilerinde hem de medyanın çalışma ve anlatı düzleminde yapısal olarak birçok ideolojiyi içinde taşımaktadır. Bireysellik, tüketimcilik, eril dil ve ırksal ayrımlar bunlardan bazılarıdır. Medya metinleri örtülü bir şekilde ihtiva ettikleri bu anlamları farklı temsiller üzerinden toplumsal alana sunarak zaman içerisinde bunların doğallaşmasına ve sistemin yeniden üretimini sağlamaktadır. Araştırma verilerinin alındığı dönemde Masterchef Türkiye finalisti olan Cemre Uyanık'ın programın 62. Bölümündeki açıklamaları kadının kapitalist sistem içerisindeki konumunu ortaya koymaktadır. “...Kadınların bir şeyler yapabildiğini göstermek için buradayım. Türkiye'de kadın aşçı olmak gerçekten çok zor. İş bulamadım, eğitimlerim var; bazıları niye bu kadar okudun ki dedi. Okumak bile benim için suç oldu. Gerçekten yetenekli olduğunuzu anlamak istemiyorlar. Yeteneğimi göstermek istiyorum...”. Uyanık’ın sözlerinden eğitimli ve kendi ayakları

17 https://www.pinar.com.tr/medya_merkezi/detay/Sef-Danilo-Zanna-\%E2\%80\%9CPinar-Chefisecti/3727/5174/0 
üstünde durabilen kadınlar da dahil olmak üzere kadınların modern toplumsal yaşam içerisinde yaşadıkları zorluklar görülmektedir. Özellikle gerek gündelik hayatta gerekse bu tür şov programları içerisinde mutfağın güç ve kuvvet gerektiren bir yer olarak tanımlanması cinsiyetçi bir tavır olarak yorumlanabilir. Yurtdışında yapılan bir çalışma bu konudaki ayrımcılığı ortaya koymaktadır. Buna göre çağdaş toplumlarda mutfak televizyonunun toplumsal işlevine odaklanan bir akademik çalışmada televizyon yemek şovlarının mutfakla ilgili hem pratik hem de estetik bilgiler vermesi dışında cinsiyet, ideoloji, etnisite ve ulusal kimlik gibi pek çok anlamı bulunduğu ve toplumsal alanda anlam kategorileri inşa ettiği vurgulanmaktadır (De Solier, 2006, s. 479).

Analizde ele alınan ikinci genel kategori tüketim toplumu içerisinde öne çıkan uzman bilgisi, yaşam tarzları ve gösteri temalarıdır. Her iki programda öne çıkan uzman bilgisi hem tüketim toplumunun hem de tematik televizyon yayıncılı̆̆ının sürdürülmesinde gerekli bir unsur olarak belirmektedir. Uzman bilgisi, modern toplumsal yaşam içerisinde araçsallaşarak gündelik hayatın farklı alanlarına nüfuz etmiş̧ir. Bu alanlardan biri de insanın temel fizyolojik gereksinimi olan beslenme etkinliği ile ilişkili olan gastronomi alanıdır. Her iki yarışma programında şef ve koordinatör şefler neoliberal piyasa koşulları içerisinde en iyi otellerde çalışmış ya da "executive" şef pozisyonunda çalışmakta olan kişilerdir. Somer Sivrioğlu gibi bazı şeflerin ise uluslararası piyasa koşullarına göre işler durumda bulunan işletmeci ya da şefi konumunda bulundukları restoranları vardır. Yarışma süreçlerinde görüldüğü üzere jüri üyesi şeflerin, sürekli üzerlerinde durarak dile getirmiş oldukları söylemlerinin başında, edinmiş oldukları yurtdışı iş tecrübeleri ve neoliberal erkler tarafından düzenlenmiş olan gastronomi alanındaki iyi mesleki pozisyonlarıdır. Şeflerin konumları sürekli olarak yarışmacı ve izleyicilere söylem ya da örnekler yoluyla iletilerek kazanmış oldukları ayrıcalıklı pozisyon vurgulanmaktadır. Jüri üyeleri gastronomi alanına ait bilgileri yarışmacılara aktardıklarını vurgularken yarışmacılar ise süreç içerisinde bilgi birikimlerinin arttı̆̆ını vurgulamaktadır. Bauman, uzmanlığa olan genel talebin gittikçe arttığını belirterek, yaşam dünyalarının artık, uzmanlar ve ürünlerinin yardımı olmaksızın sürdürülemeyeceğine ilişkin bir kanının oluştuğunu vurgulamaktadır. Uzmanlar, modern ve ötesi toplum formlarında bireyleri belirsizliklerden kurtulmanın dolayısıyla yaşam dünyalarını denetlemenin araç ve yetkilerini vaat etmektedir (2003, s. 283). Bu anlamda tüketim toplumu içerisinde geçerli ve moda bir meslek haline gelen aşçllı konusunda eğitim almak ve alanında uzman kişiler ile birlikte olmak neoliberal sistemin ekonomik belirsizlikleri içerisinde bireylerin yaşam dünyalarına mesleki anlamda istikrar kazandıracak bir hamle olarak yorumlanabilir.

Uluslararası literatürde izleyicilerin yemek programları ve ünlü şeflerle ilgili tutum ve inançlarını belirlemeye yönelik birçok araştırma olmasına rağmen, Türkiye'de bu konuyla ilgili yapılmış çalışma sayısı sınırıdır. Bu alanda yapılan akademik çalışmalardan birinin elde ettiği sonuçlar bu programların toplumsal işlevinin yorumlanmasına katkı 
sağlayacaktır ${ }^{18}$. Yapılan bu çalışmada görüldüğü gibi medya ürünün içerdiği bilginin alımlanması ve bunun davranışa dökülmesi arasında her zaman doğrusal bir ilişki yoktur. Bu örnekte olduğu gibi gastronomi alanına ait en küçük ortak kültüre ${ }^{19}$ sahip olmak için programlar izlense dahi bu bilgilerin gündelik yaşamda uygulamaya geçmesi çoğu kez gerçekleşmemektedir. Bu durumun altında yatan nedenlerden biri tüketim kültürü içerisinde farklı bilgi alanlarına olan ihtiyacın sistem tarafından manipüle edilerek yapay bilgi gereksinimlerinin yaratılmasıdır. Bu bilgi parçacıkları toplumsal alanda sisteme eklemlenmeyi ve onu yeniden üretmeyi sağlarken bireysel düzlemde gündelik yaşam içerisinde diğer insanlarla etkileşime girmeyi ve sosyalleşmeyi sağlamaktadır.

Masterchef Türkiye yarışmacılarından, Güzide Mertcan, üç çocuk annesi uzman estetisyen olarak ablasıyla bir tekstil atölyesi işletmektedir. Aynı yarışmadaki Eda Karabulut Nayir, pastacı kalfasıdır. The Taste Türkiye yarışmacısı Güler Ezgi Özel ise diyetisyendir. Farklı meslek gruplardan yarışmaya dahil edilen katılımcılar, bu durumu vurgulayarak yarışma sürecinde ve sosyal medya hesaplarından uzmanlığı doğrultusundaki mesleki bilgi ve tecrübelerinin paylaşımını yapmaktadır. Bu durumun kavramsal olarak iki boyutu bulunmaktadır. İlk olarak Debord'un bütünleşik gösteri kavramı bu toplumsal gerçekliği karşılamaktadır; postmodern kültür içerisinde toplumsalın her alanı zorunlu ve tek yönlü bir görselleşme sürecine tabidir denilebilir. İkinci olarak Henry Jenkins medya teknolojilerinin dijital gündelik hayatla ilişkisi için yöndeşme "yakınsama" kavramını ortaya koymuştur. Çoklu platformlardaki içerik akışı, çoklu medya endüstrileri arasındaki iş birliği ve izleyicilerin mobil olarak eğlence içeriklerine ulaşma deneyimi yöndeşme kavramının içinde yer almaktadır (2006, s. 2). Katılımcılar farklı medya platformlarını kullanarak kamusal alandaki görünürlüklerini artırmaktadır.

Masterchef Türkiye yarışmacılarından Güzide Mertcan sosyo-ekonomik olarak üst seviyede bir aileye sahiptir. Gösterişli evi, kıyafetleri ve yaşam tarzlarıyla öne çıkmıştır. Popüler kültür, tüketim temelli bir yapı olarak metaların, anlamların ve simgelerin para ekonomisi üzerinden değiş tokuş edildiği toplumsal bir örgütlenme şeklidir. Tüketim ekonomisi farklı toplumsal gruplar için farklı yaşam tarzlarını piyasaya sürmektedir. İnsanları birbirinden farklı kılan davranış tarzlarıdır. Yaşam tarzı genellikle tüketimin sosyal organizasyonu olarak tanımlansa da David Chaney, yaşam tarzlarının

18 Araştırma sonucuna göre katılımcıların yarısından fazlası tarifler ve pişirme yöntemleriyle ilgili bilgi almak için bu programları izlediklerini belirtmişlerdir. Katılımcıların \%22,7si yemek pişirme becerilerini geliştirmek için televizyon programından aldıkları tarifleri denediklerini belirtirken aynı oranda \%22,7si ise hiçbir zaman bir televizyon yemek programından tarif kullanmadıklarını belirtmiştir. Katılımcılar yemek programlarını ve şefleri eğitici ve öğretici amaçla takip etseler dahi uygulamada isteksiz görünmektedirler. Katılımcılar şeflerin nitelikli olduklarını düşünmelerine rağmen bu programlarda beslenme ve diyet önerileri sunmadıklarını ayrıca bu programların beslenme rejimleri üzerinde bir etkisi olmadığını bildirmektedir (Demir ve Kiz1lırmak, 2019, s. 1860-1861).

19 Jean Baudrillard Tüketim Toplumu adlı eserinde tüketimi sadece nesnelerle değil aynı zamanda kolektivite ve dünya ile bir ilişsi kurma şekli olarak tanımlamaktadır. Televizyon modern toplumlarda tüketim ekonomisinin işlemesine yönelik bir takım işlevsel bilgileri bünyesinde taşımaktadır. "En Küçük Ortak Kültür" (EKOK) olarak adlandırılan bu işlevsel bilgi parçacıkları toplumsal alanda televizyon üzerinden dolaşıma sokulmaktadır. Baudrillard'a göre kitle iletişimini tanımlayan, teknik araçla EKOK'un birleşimidir (2004, s. 127-129). 
normatif görünümlerine vurgu yapmıştır. Bu bağlamda tüketim kişilerin kendilerini tanımladığı ve kimlik kazandığı her türlü toplumsal aktiviteyi tanımlamaktadır (1999, s. 14-15). Bu bağlamda Güzide Mertcan'ın toplumsal kimliği tüketim nesneleriyle girdiği ilişki üzerinden belirlenirken televizyon kişiliği olarak toplumsal alandaki bir yaşam tarzının da temsili haline gelerek stereotipik bir görünüm kazanmaktadır.

Her iki yarışma programı uluslararası formattaki reality programları olmalarına rağmen içerik olarak bazı farkları da mevcuttur ${ }^{20}$. Yarışmalar içerisinde özel günler kurmaca anlatı içerisinde bir fon görevi görerek anlatının çeşitlenmesini ve renklenmesini sağlamaktadır. Örneğin Masterchef Türkiye'nin 29 Ekim özel bölümünde yarışan yarışmacılar Sakarya Meydan Muharebesi Tarihi Milli Parkının içerisindeki alanda performanslarını sergilemişlerdir. Mustafa Kemal Atatürk'ün en sevdiği yemekler o güne özel yapılmıştır. Yapılan yemekler gazilere, 15 Temmuz gazilerine ve orada bulunan özel misafir statüsünde yer alan insanlara ikram edilmiş bunun karşılığında misafirlerden yedikleri yemekleri puanlamaları istenmiştir. Yine her iki programda gastronomi alanında ülkemizde söz sahibi olan Gaziantep ve Konya gibi kentlere gidilerek yarışmalar bu otantik mekânlarda yapılmaktadır. Yerellik vurgusunun gözlemlendiği bir başka örnek The Taste Türkiye programında gözlemlenmiştir. Programa her hafta dışarıdan ünlü şefler ya da neoliberal ekonomi içerisinde başarılı işletmeciler konuk olarak katılmaktadır. Ünlü şef ve işletmeci Cüneyt Asan'ın görsel bir performans sergilemesi beklenirken tezgâhın başında ve önünde bir parça but bulunurken yaptığı konuşma dikkat çekicidir ${ }^{21}$.

Ele alınan gastronomi yarışmaları uluslararası formatın bir gereği olarak kozmopolit unsurlar ile yerel unsurları bir arada harmanlayarak izleyicilerle buluşturmaktadır. Burada kültürel ve tarihi alan bir yandan televizyon anlatısının içerisinde araçsallaşarak dramatik anlatıya dekor işlevi görürken diğer yandan postmodern kültürün eklektik tarzı içerisinde tüketilmesi gereken yeni ve farklı bir unsur olarak öne çıkmaktadır. Bu bağlamda Tomlinson'nun küreselleşme ve kültür arasındaki bağıntıları analiz ederken kültürü sadece maddi malların tüketimi değil aynı zamanda varoluşsal olarak anlamlı bir sembolleştirme ve deneyim alanı olarak tanımlaması önemlidir. Yaşam tarzlarının metalaşması ve gündelik hayatın estetize edilmesi sürecinde günlük deneyim

20 Örneğin The Taste Türkiye'de şeflerin takımları yarışırken, Masterchef Türkiye'de ise her hafta yarışmacıların kendi aralarında kurdukları takımlar yarışmaktadır. Dokunulmazlık oyunlarına kadar takım yarışmaları devam etmektedir. Masterchef Türkiye programında takım halinde yarışan yarışmacıların performanslarını haftanın bir gününde stüdyo dışında belirlenen bir alanda sergilemeleri ve halk tarafindan değerlendirilmeleri söz konusudur.

21 Yüksek sesle şunları dile getirmiştir; Anadolu...Anadolu ne demektir? Dünya'ya açılan pencere, dünyaya açılan kapı. Dünyada bugün yemekti, pirinçti, buğdaydı ne varsa bu ülkede bu güzel ülkeden dünyaya açılmıştır. Bu güzel ülkenin penceresinden dışarı açılmıştır. (Der ve bütün şefler yarışmacılar kafa sallar.) Ve unutmayın ki bu topraklar yaşadığımız bu topraklar Türkiye Cumhuriyeti’nin kapsadığı bu topraklar emin olun kutsal topraklardır. (Herkes onaylar). Biz bu topraklar için ne can verdik ne kadar kan döktük. Onun için biz ülkemizi çok seviyoruz. Yemekleri yaparken bu duygu ve düşüncelerle yemeklerinizi yapın. Ruhunuzu koymalısınız. Ruhunuzla yapın. (Der ve elindeki eti (but) 44 saniye içerisinde kemiklerinden ayırır.) The Taste Türkiye 20.bölüm. Cüneyt Asan Show 
medya üzerinden gerçekleşirken buna bağlı bir yersiz-yurtsuzluk ortaya çıkmaktadır. Televizyon bu toplumsal yaşam içerisinde dolayımlanmış-sözde deneyimler kurmaktadır. Bu iletişim tarzının özelliği diyalojik olmaktan çok monolojik olmasıdır (2004, s. 121, 154-159, 271). Tomlinson'nun düşünceleri takip edildiğinde tüketim kültürünün yapılandırılmış bir alan olarak küresel düzeyde çeşitli eşitsizlikleri içerisinde taşıdığı görülmektedir. Bu eşitsizliklerin üretilmesi ve sürdürülmesi sürecinde genelde kitle iletişim araçları özelde ise yaygınlığı ile televizyon ideolojik bir işleve sahiptir. Gösteri toplumsal alanda birbirinden çok farklı bireylerin beklentilerini bir kenara koyarak kısa süreliğine bir araya geldikleri cemaatler oluşturmaktadır. Bireysel endişelerin bırakılarak seyirlik bir nesne etrafinda örgütlenen bu toplumsal gruplar gündelik hayatın rutinliğinin dışına çıkmak için araçsal öneme sahip olan vestiyer ya da karnaval cemaatlerdir (Bauman, 2018, s. 284-286). Bu bağlamda gastronomi yarışmalarındaki yerel kültürel öğeler ya da otantik yapılar ele alındığında toplumların kolektif hafizasında yer eden belirli mekânlara yapılan yolculuk boyunca seyirlik bir nesne etrafında oluşan bir toplumsallaşma şekli olduğu görülmektedir.

\section{Sonuç}

Neoliberal piyasa ekonomisinin desteklediği tüketim toplumunda, bireylerin kültürel alanda yaşam tarzları, yiyip içtikleri, giysileri sembolik bir anlama sahiptir. Genelde kitle iletişim medyası özelde ise yaygınlığı ile televizyon içinde yaşanılan dönemin egemen değerlerinin geniş kitleler ile paylaşıldığ 1 bir platform olarak öne çıkmaktadır. Televizyon anlatısı içerisinde reality programları eklektik ve melez yapıları gereği farklı kültürel unsurların bir arada harmanlanabileceği ideal bir alandır. Tüketim toplumunda gündelik hayat ideolojisinin üretim ve yeniden üretim süreçlerinde bu programlar önemli işlevlere sahiptir. Gündelik hayatın estetize edildiği bir süreçte söz konusu programlar kimi zaman gündelik hayatın tüketime dayalı etkinliği içinde bir anlam yaratma alanı kimi zaman ise neoliberal kapitalist sistemin eşitsiz toplumsal gelişiminde bireylerin hayat projelerinde bir uğrak noktası ya da durak haline gelerek sisteme eklemlenme konusunda araçsal bir işleve sahip olmaktadır. Bu süreçte televizyon üzerinden toplumsal alanda dolaşıma sokulan metalar, yaşam tarzları, semboller ve anlamların oluşturduğu eşitsiz durum küresel düzeyde eğlence içerikli temalar içerisinde eriyip yok olmaktadır. Tüketim toplumunda fizyolojik bir gereksinim olarak beslenme etkinliği de gastronomi alanı içerisinde araçsallaşarak toplumsal dolaşıma sokulmaktadır. Bir uzmanlık alanı olarak gastronomi, ele alınan uluslararası formattaki reality yarışma programlarındaki gibi popüler kültür içerisinde bütünsel gösterinin bir parçası olarak öne çıkmaktadır.

Oluşan yeni toplumsal yapıda beslenme etkinliği ya da gastronomi tarihsel süreç içerisindeki sosyolojik ve antropolojik anlamlarının ötesine geçerek tüketim toplumunun gerekliliklerine göre belirlenmiş bir kod evreni içerisinde anlam bulmaktadır. $\mathrm{Bu}$ 
durumda yemek, reality yarışma programında ya da herhangi bir dijital platformda sunulan estetik bir sunum olarak öne çıkarken bir anlamda yemek simulakrı haline gelmektedir. Çünkü onu toplumsala bağlayan tüm unsurlarından arındıktan sonra geriye kalan renkli ve estetik unsurlardan oluşan kurgusal bir sunumdur. Tüm bu kültürel yapı içerisinde söz konusu programlar hala bir takım küresel ve yerel temaları tekrarlayarak onları gastronomi içeriğinde eriterek anlam oluşturmaya çalışmaktadır. Ancak söz konusu programlar sona erdiği anda eklektik olarak bir araya getirip anlam vermeye çalıştı̆̆ kültürel öğeler birbirinden ayrılarak televizyon aracının soğuk ekranında yok olmaktadır.

Özetlenecek olursa reality program türleri içerisinde ya da yarışma programlarında gastronomi alanı televizyonun baskın gösteri söyleminin bir parçası olarak işlev görmektedir. Beslenme alanına ait bilgi bu yapı içerisinde ekonomik yanının dışında kültürel anlamda da kapitalizme eklemlenirken yemeğin taşıdığı sembolik anlam, ilişki türleri ve etkileşim ritüelleri medya üzerinden verilen temsiller yoluyla dolayımlanmakta ve içselleştirilmektedir. Uluslararası formata sahip bu programlar bir yandan kozmopolit yaşama ilişkin temsilleri bünyelerinde bulundururken diğer yandan yerel kültürel öğeler, tatlar ve ambiyanslarla ilişki içerisine girerek onların modernize edilmiş temsillerini beyaz ekran aracılı̆̆ıly kitlelerle paylaşmaktadırlar. Bu ise televizyonun bir meta anlatı "üst-dil" olarak her türlü ideolojik söylemin üzerinde küresel kapitalist sistemin sürdürülmesinde işlevsel bir araç olduğunu göstermektedir.

Hakem Değerlendirmesi: Dış bağımsız.

Çıkar Çatışması: Yazarlar çıkar çatışması bildirmemiştir.

Finansal Destek: Yazarlar bu çalışma için finansal destek almadığını beyan etmiştir.

Peer-review: Externally peer-reviewed.

Conflict of Interest: The authors declare no potential conflicts of interest with respect to the research, authorship, and/or publication of this article.

Grant Support: The authors received no financial support for the research, authorship, and/or publication of this article.

\section{Kaynakça/References}

Akarçay, E. (2016). Beslencenin sosyolojisi, orta sınıfların yeme içme ve eğlence örüntüleri. Phoenix Yayınlar1.

Andrejevic, M. (2004). Reality TV work of being watched. Rowman \& Littlefield.

Ashley, B., Hollows, J., Jones, S., \& Taylor, B. (2004). Television chefs. In B. Ashley, J. Hollows, S. Jones, \& B. Taylor (Eds.), Food and cultural studies (pp. 171-187). Routledge.

Baudrillard, J. (2004). Tüketim toplumu (H. Deliceçaylı \& F. Keskin, Çev.). Ayrıntı Yayınları.

Baudrillard, J. (2005). Şeytana satılan ruh ya da kötülüğün egemenliği (O. Adanır, Çev.). Doğu Batı Yayınları.

Bauman, Z. (2003). Modernlik ve müphemlik (İ. Türkmen, Çev.). Ayrıntı Yayınları.

Bauman, Z. (2018). Akışkan modernite (S. O. Çavuş, Çev.). Can Yayınları. 
Beardsworth, A., \& Keil, T. (2011). Yemek sosyolojisi - Yemek ve toplum çalı̧̧masına bir davet (A. Dede, Çev.). Phoenix Yayınları.

Belge, M. (2016). Tarih boyunca yemek kültürü. İletişim Yayınları

Bilgin, N. (2006). Sosyal bilimlerde içerik analizi. Siyasal Kitabevi.

Bottomore, T. (2013). Frankfurt okulu ve eleştirisi (Ü. H. Yolsal, Çev.). Say Yayınları.

Bowrey, K. (2013). The manufacture of 'authentic' buzz and the legal relations of MasterChef. In D. Hunter, R. Lobato, M. Richardson, \& J. Thomas, Amateur media social, cultural and legal perspectives. (p. 73). Routledge.

Burton, G. (1995). Görünenden fazlası medya analizlerine giriş (N. Dinç, Çev.). Alan Yayıncılık.

Chaney, D. (1996). Lifestyles. Routledge.

Curnutt, H. (2016). Cooking on reality TV: Chef - Participants and culinary television. In P. Bradley (Ed.), Food, media and contemporary culture: The edible image (pp. 144-164). Palgrave Macmillan.

Çakır, M. (2014). Görsel kültür ve küresel kitle kültürü. Ütopya Yayınevi.

Çelenk, S. (2005). Televizyon, temsil, kültür 90'll yillarda sosyokültürel iklim ve televizyon içerikleri. Ütopya Yayınları.

Çetinkaya, N. (2018). Gastronominin tarihsel gelişimi, tarih öncesi çağlar. A. Akbaba ve N. Çetinkaya (Ed.), Gastronomi ve yiyecek tarihi içinde (s. 93-105). Detay Yayıncılık.

Debord, G. (2006). Gösteri toplumu ve yorumlar (A. Ekmekçi \& O. Taşkent, çev.). Ayrıntı Yayınları.

Deery, J. (2012). Consuming reality The commercialization of factual entertainment. Palgrave Macmillan.

Deery, J. (2004). Reality TV as advertainment. Popular Communication, 2(1), 1-20. http://doi. org/10.1207/s15405710pc0201_1

Demir, Y. \& Kızılırmak, İ. (2019). İzleyicilerin televizyon yemek programları ve ünlü şeflerle ilgili inanç ve tutumlarını değerlendirmeye yönelik bir araştırma. Journal of Tourism and Gastronomy Studies, 7(3), 1852-1866.

De Solier, I. (2005). TV dinners: Culinary television, education and distinction. Continuum Journal of Media \& Cultural Studies, 19(4), 465-481. http://doi.org/10.1080/10304310500322727

Dowd, D. (2013). Kapitalizm ve kapitalizmin iktisadı (C. Gerçek, Çev.). Yordam Kitap.

Douglas, M. (1972). Deciphering a meal. The MIT Press, 101(1), 61-81.

Duménil, G. \& Lévy, D. (2009). Kapitalizmin marksist iktisadı (S. Pelek, Çev.). İletişim Yayınları.

Dursun, Ç. (2013). İletişim kuram kritik. İmge Yayıncılık.

Ellul, J. (1998). Sözün düşüşü (H. Arslan, Çev.). Paradigma Yayınları.

Finkelstein, J. (1999). Foodatainment. A Journal of the Performing Arts, 4(1), 130-136. http://doi. org/10.1080/13528165.1999.10871653

Fiske, J. (1996). Popüler kültürü anlamak (S. İrvan, Çev.). Ark Yayınları.

Foucault, M. (2006). Hapishanenin doğuşu (M. A. Kılıçbay, Çev.). İmge Kitabevi.

Ganguly, L. (2012). Global television formats and the political economy of cultural adaptation: Who wants to be a millionare? In India. In T. Oren \& S. Shahaf (Eds.), Global television formats: Understanding television across borders (pp. 323-346). Routledge.

Giddens, A. (2016). Kapitalizm ve modern sosyal teori (Ü. Tatlıcan, Çev.). İletişim Yayınları. 
Goody, J. (2013). Yemek, mutfak, sınıf karşılaş̧tırmalı sosyoloji çalışması (M. G. Güran, Çev.). Pinhan Yayınc1lik.

Gökçe, O. (2006). İ̧̧erik analizi kuramsal ve pratik bilgiler. Siyasal Kitabevi.

Gürsoy. D. (2018). Deniz Gürsoy’un gastronomi tarihi. Oğlak Yayıncılık.

Harvey, D. (2010). Postmodernliğin durumu (S. Savran, Çev.). Metis Yayınları.

Harvey, D. (2012a). Sermayenin mekanları eleştirel bir coğrafyaya doğru (B. Kıcır, D. Koç, K. Tanrıyar, \& S. Yüksel, Çev.). Sel Yayıncılık.

Harvey, D. (2012b). Sermaye muamması kapitalizmin krizleri (S. Savran, Çev.). Sel Yayıncılık.

Harvey, D. (2015). Neoliberalizmin kısa tarihi (A. Onacak, Çev.). Sel Yayınları.

Hatipler, M. (2016). Ekonomik boyutuyla görsel kültür ve kültür endüstri. Değişim Yayınları.

Işın, M. P. (2019). Avcllıktan gurmeliğe yemeğin kültürel tarihi. Yapı Kredi Yayınları.

Jenkins, H. (2006). Convergence culture. New York University Press.

Kanık, İ. (2016). Gastro gösteri popüler kültür ürünlerinde yemeğin kültürel gösterisi. Ayrıntı Yayınlar1.

Kaplan, Y. (1992). Öykü-anlatma ve mit-üretme aracı olarak televizyon (G. Kaplan, Çev.). Ağaç Yayınlar1.

Kaya, Y, S. (2011). Reality TV programları gerçekten gerçek. A. Kotaman, A. S. Uğursoy, \& A. Avcı (Ed.), "Dizim başladı! Kapat, sonra anlatırım” televizyonda hikâye anlatıcılı̆̆ı içinde (s. 115-143). H2O Yayıncılik.

Lefebvre, H. (2010). Modern dünyada gündelik hayat (I. Gürbüz, Çev.). İstanbul: Metis Yayınları.

Lewis, T. (2010). Mobile makeovers: Global and local lifestyles and identities in reality formats. In A. Hetsroni (Ed.), Reality television: Merging the global and the local (pp. 189-211). Nova Science Publishers Inc.

Marx, K., \& Engels, F. (2013a). Komünist parti manifestosu (S. Jabban, Çev.). Patikakitap.

Marx, K. \& Engels, F. (2013b). Alman İdeolojisi (T. Ok \& O. Geridönmez, Çev.). Doğa Basım Yayın.

Mutlu, E. (1991). Televizyonu anlamak. Gündoğdu Yayınları.

Postman, N. (2004). Televizyon: Öldüren eğlence gösteri çağında kamusal söylem (O. Akınhay, Çev.). Ayrıntı Yayınları.

Postone, M. (2018). Çağdaş dünyayı kuramsallaştırma: Robert Brenner, Giovanni Arrighi, David Harvey. In R. Albritton, B. Jessop, \& R. Westra (Eds.), Siyasi iktisat ve küresel kapitalizm 21. Yüzyıl, bugün ve yarın içinde (C. Cemgil, Çev., s. 11-29). İstanbul Bilgi Üniversitesi Yayınları.

Robins, K. (1999). Imaj görmenin kültür ve politikası (N. Türkoğlu, Çev.). Ayrıntı Yayınları.

Simmel, G. (2011). Modern kültürde çatışma (T. Bora, N. Kalayc1, \& E. Gen, Çev.). İletişim Yayınları.

Smith, P. (2005). Kültürel kuram (S. Güzelsarı \& İ. Gündoğdu, Çev.). Babil Yayınları.

Tomlinson, J. (2004). Küreselleşme ve kültür (A. Eker, Çev.). Ayrıntı Yayınları.

Yıldırım, A. \& Şimşek, H. (2000). Sosyal bilimlerde nitel araştırma yöntemleri. Seçkin Yayınları.

Wernick, A. (1991). Promotional culture. Sage Publications. 